\title{
MIRD Pamphlet No. 22 (Abridged): Radiobiology and Dosimetry of $\alpha$-Particle Emitters for Targeted Radionuclide Therapy*
}

George Sgouros ${ }^{1}$, John C. Roeske², Michael R. McDevitt ${ }^{3}$, Stig Palm4, Barry J. Allen ${ }^{5}$, Darrell R. Fisher ${ }^{6}$, A. Bertrand Brill ${ }^{7}$, Hong Song ${ }^{1}$, Roger W. Howell ${ }^{8}$, and Gamal Akabani ${ }^{9}$

In collaboration with the SNM MIRD Committee: Wesley E. Bolch, A. Bertrand Brill, Darrell R. Fisher, Roger W. Howell, Ruby F. Meredith, George Sgouros (Chair), Barry W. Wessels, and Pat B. Zanzonico

${ }^{1}$ Department of Radiology and Radiological Science, Johns Hopkins University, Baltimore, Maryland; ${ }^{2}$ Department of Radiation Oncology, Loyola University Medical Center, Maywood, Illinois; ${ }^{3}$ Departments of Medicine and Radiology, Memorial SloanKettering Cancer Center, New York, New York; ${ }^{4}$ Dosimetry and Medical Radiation Physics Section, International Atomic Energy Agency, Vienna, Austria; ${ }^{5}$ Centre for Experimental Radiation Oncology, St. George Cancer Centre, Kogarah, Australia; ${ }^{6}$ Radioisotopes Program, Pacific Northwest National Laboratory, Richland, Washington; ${ }^{7}$ Department of Radiology, Vanderbilt University, Nashville, Tennessee; ${ }^{8}$ Division of Radiation Research, Department of Radiology, New Jersey Medical School Cancer Center, University of Medicine and Dentistry of New Jersey, Newark, New Jersey; and ${ }^{9}$ Department of Nuclear Engineering, Texas A\&M University, College Station, Texas

The potential of $\alpha$-particle emitters to treat cancer has been recognized since the early 1900s. Advances in the targeted delivery of radionuclides and radionuclide conjugation chemistry, and the increased availability of $\alpha$-emitters appropriate for clinical use, have recently led to patient trials of radiopharmaceuticals labeled with $\alpha$-particle emitters. Although $\alpha$-emitters have been studied for many decades, their current use in humans for targeted therapy is an important milestone. The objective of this work is to review those aspects of the field that are pertinent to targeted $\alpha$-particle emitter therapy and to provide guidance and recommendations for human $\alpha$-particle emitter dosimetry.

Key Words: $\alpha$-particle emitters; human $\alpha$-particle emitter dosimetry; targeted $\alpha$-particle emitter therapy

J Nucl Med 2010; 51:311-328

DOI: 10.2967/jnumed.108.058651

O $\alpha$-particle-emitting radionuclides, which have been the subject of considerable investigation as cancer therapeutics (1-8). In the context of targeted therapy, $\alpha$-particle emitters have the advantages of high potency and specificity. These advantages arise from the densely ionizing track and short path length of the emitted positively charged helium nucleus in tissue. The practical implication of these features, as well as the distinction between $\alpha$-particles and the more widely

Received Sep. 29, 2008; revision accepted Jun. 29, 2009.

For correspondence or reprints contact: George Sgouros, Department of Radiology and Radiological Science, CRB II 4M61/1550 Orleans St., School of Medicine, Johns Hopkins University, Baltimore, MD 21231.

E-mail: gsgouros@jhmi.edu

*Unabridged version of this document is available at: http://interactive. snm.org/index.cfm?PageID =1110\&RPID =2199\&FileID =144234.

COPYRIGHT $\odot 2010$ by the Society of Nuclear Medicine, Inc. used $\beta$-particle emitters for targeted radionuclide therapy, is that it is possible to sterilize individual tumor cells solely from self-irradiation with $\alpha$-particle emitters. This is generally not possible with $\beta$-particle emitters given achievable antibody specific activity, tumor-cell antigen expression levels, and the need to avoid prohibitive toxicity (5). These attributes combine to provide the fundamental strength and rationale for using $\alpha$-particle-emitting radionuclides for cancer therapy. Current approaches to cancer treatment are largely ineffective once the tumor has metastasized and tumor cells are disseminated throughout the body. There is also increasing evidence that not all tumor cells are relevant targets for effective tumor eradication and that sterilization of a putative subpopulation of a small number of tumor stem cells may be critical to treatment efficacy (9). The eradication of such disseminated tumor cells, or of a subpopulation of tumor stem cells, requires a systemic targeted therapy that is minimally susceptible to chemo- or radioresistance, is potent enough to sterilize individual tumor cells and microscopic tumor cell clusters (even at a low dose-rate and low oxygen tension), and exhibits an acceptable toxicity profile (10). $\alpha$-Particle-emitting radionuclides address this critical need. To accomplish these goals, a reliable, cost-effective source of $\alpha$-particle emitters is needed for research and development and for routine use in clinical practice. Improved chemical labeling and stability will be needed to achieve the desired biodistribution and associated dose distribution necessary for successful therapy with acceptable acute and long-term toxicities. These limitations have slowed the development and clinical use of $\alpha$-emitter targeted therapy relative to the use of $\beta$ - and Auger-electron-emitting radionuclides. 
The first clinical trial of an $\alpha$-particle emitter in radiolabeled antibody therapy used ${ }^{213} \mathrm{Bi}$ conjugated to the antileukemia antibody HuM195 and was reported in 1997 $(11,12), 4$ years after ${ }^{213} \mathrm{Bi}$ was first suggested for therapeutic use (13). This trial was followed by a human trial of the antitenascin antibody 81C6 labeled with the $\alpha$-emitter ${ }^{211} \mathrm{At}$ in patients with recurrent malignant glioma (14). In addition to these 2 antibody-based trials, a clinical trial of unconjugated ${ }^{223} \mathrm{Ra}$ against skeletal metastases in patients with breast and prostate cancer was recently completed (15). More recently, a patient trial of ${ }^{211}$ At targeting ovarian carcinoma has been initiated (16). Future trials of $\alpha$-emitters are anticipated using antibodies labeled with ${ }^{211} \mathrm{At}$ or ${ }^{213} \mathrm{Bi}$ and directed against tumor neovasculature (17-19). A conjugation methodology for ${ }^{225} \mathrm{Ac}$ was recently described
(20), and a phase I trial of this radionuclide with the antileukemia antibody HuM195 in leukemia patients has recently been initiated (21). Table 1 summarizes clinical trials involving $\alpha$-particle-emitting radiopharmaceuticals.

This report focuses on $\alpha$-emitter dosimetry as it relates to human use in targeted therapy. A review of $\alpha$-particle radiobiologic studies is provided with a focus on the radiobiology of $\alpha$-emitters that are relevant to targeted therapy in humans. Closely related to the radiobiology of $\alpha$-emitters is the concept of relative biological effectiveness (RBE), which is also reviewed. The dosimetry of $\alpha$-emitters has been addressed in a large number of publications. The criteria for microdosimetry, the different approaches for performing such calculations, and selected studies in which such calculations have been performed are briefly described.

\section{TABLE 1. Summary of Recently Reported Clinical Trials Using $\alpha$-Particle Emitters}

\begin{tabular}{|c|c|c|c|c|}
\hline Radionuclide & $\begin{array}{l}\text { Delivery } \\
\text { vehicle }\end{array}$ & $\begin{array}{l}\text { Type of } \\
\text { cancer }\end{array}$ & Comments & Reference \\
\hline \multirow[t]{2}{*}{${ }^{211}$ At } & $\begin{array}{l}\text { Antitenascin } \\
\text { lgG }\end{array}$ & $\begin{array}{c}\text { Glioblastoma } \\
\text { multiforme }\end{array}$ & $\begin{array}{l}\text { Ongoing phase I trial using surgical } \\
\text { cavity injection of labeled antitenascin } \\
\text { lgG; median survival of } 60 \text { wk; } 2 \text { patients } \\
\text { with recurrent glioblastoma multiforme } \\
\text { survived nearly } 3 \text { y }\end{array}$ & 14 \\
\hline & $\mathrm{MX} 35 \mathrm{~F}(\mathrm{ab})_{2}$ & Ovarian carcinoma & $\begin{array}{l}\text { Ongoing phase I trial using } \mathrm{MX} 35 \mathrm{~F}\left(\mathrm{ab}^{\prime}\right)_{2} \\
\text { bone marrow and peritoneal absorbed } \\
\text { doses of } 0.08 \text { and } 8 \mathrm{mGy} / \mathrm{MBq} \text {, respectively }\end{array}$ & 16 \\
\hline \multirow[t]{4}{*}{${ }^{213} \mathrm{Bi}$} & Anti-CD33 lgG & $\begin{array}{l}\text { Myelogenous } \\
\text { leukemia (acute } \\
\text { or chronic) }\end{array}$ & $\begin{array}{l}\text { Phase I completed with no toxicity, substantial } \\
\text { reduction in circulating and bone marrow blasts; } \\
\text { phase I/II in cytoreduced patients, } 4 \text { of } 23 \\
\text { patients at very high risk showed lasting } \\
\text { complete response (up to } 12 \text { mo) }\end{array}$ & 11,21 \\
\hline & $\begin{array}{l}\text { Antineurokinin } \\
\text { receptor peptide }\end{array}$ & Glioblastoma & $\begin{array}{l}\text { Two patients treated with }{ }^{213} \mathrm{Bi} ; 1 \text { with } \\
\text { oligodendroglioma treated by distillation in } \\
\text { resection cavity alive more than } 67 \mathrm{mo}\end{array}$ & 148 \\
\hline & $\begin{array}{l}\text { Anti-CD20 IgG } \\
\text { (rituximab) }\end{array}$ & $\begin{array}{l}\text { Relapsed or } \\
\text { refractory } \\
\text { non-Hodgkin } \\
\text { lymphoma }\end{array}$ & Phase I study with 9 patients treated to date & 149 \\
\hline & $9.2 .27 \lg \mathrm{G}$ & Melanoma & $\begin{array}{l}\text { Sixteen patients; intralesional administration led } \\
\text { to massive tumor cell kill and resolution of } \\
\text { lesions; significant decline in serum marker } \\
\text { melanoma-inhibitory-activity protein at } 2 \mathrm{wk} \\
\text { after treatment }\end{array}$ & 150 \\
\hline${ }^{223} \mathrm{Ra}$ & $\mathrm{RaCl}_{2}$ & $\begin{array}{l}\text { Skeletal breast } \\
\text { and prostate } \\
\text { cancer } \\
\text { metastases }\end{array}$ & $\begin{array}{l}\text { Phase IA dose-escalation studies completed } \\
\text { involving single-dose infusion of } 46-250 \mathrm{kBq} / \mathrm{kg} \\
\text { in } 25 \text { patients with no dose-limiting hematologic } \\
\text { toxicity; phase IB study in } 6 \text { patients to } \\
\text { evaluate repeated injections ( } 2 \text { or } 5 \text { fractions) } \\
\text { totaling up to } 250 \mathrm{kBq} / \mathrm{kg} \text {; phase II randomized } \\
\text { trial in } 33 \text { patients with metastatic breast or } \\
\text { prostate cancer treated with external beam } \\
\text { plus saline or } 4 \text { times } 50 \mathrm{kBq} / \mathrm{kg} \text { dose of }{ }^{223} \mathrm{Ra} \\
\text { at } 4 \text {-wk intervals; shows significant ( }-66 \%) \\
\text { decrease in bone alkaline phosphatase compared } \\
\text { with placebo and } 15 \text { of } 31 \text { patients with } \\
\text { prostate-specific antigen decrease }>50 \% \text { from } \\
\text { baseline vs. } 5 \text { of } 28 \text { in control group }\end{array}$ & 151,152 \\
\hline${ }^{225} \mathrm{Ac}$ & Anti-CD33 lgG & $\begin{array}{l}\text { Acute } \\
\text { myelogenous } \\
\text { leukemia }\end{array}$ & $\begin{array}{l}\text { Phase I trial, ongoing, at first dose-level of } \\
18.5 \mathrm{kBq} / \mathrm{kg}(0.5 \mu \mathrm{Ci} / \mathrm{kg}) ; 1 \text { of } 2 \text { patients had } \\
\text { elimination of peripheral blasts and reduction } \\
\text { in marrow blasts }\end{array}$ & 21 \\
\hline
\end{tabular}




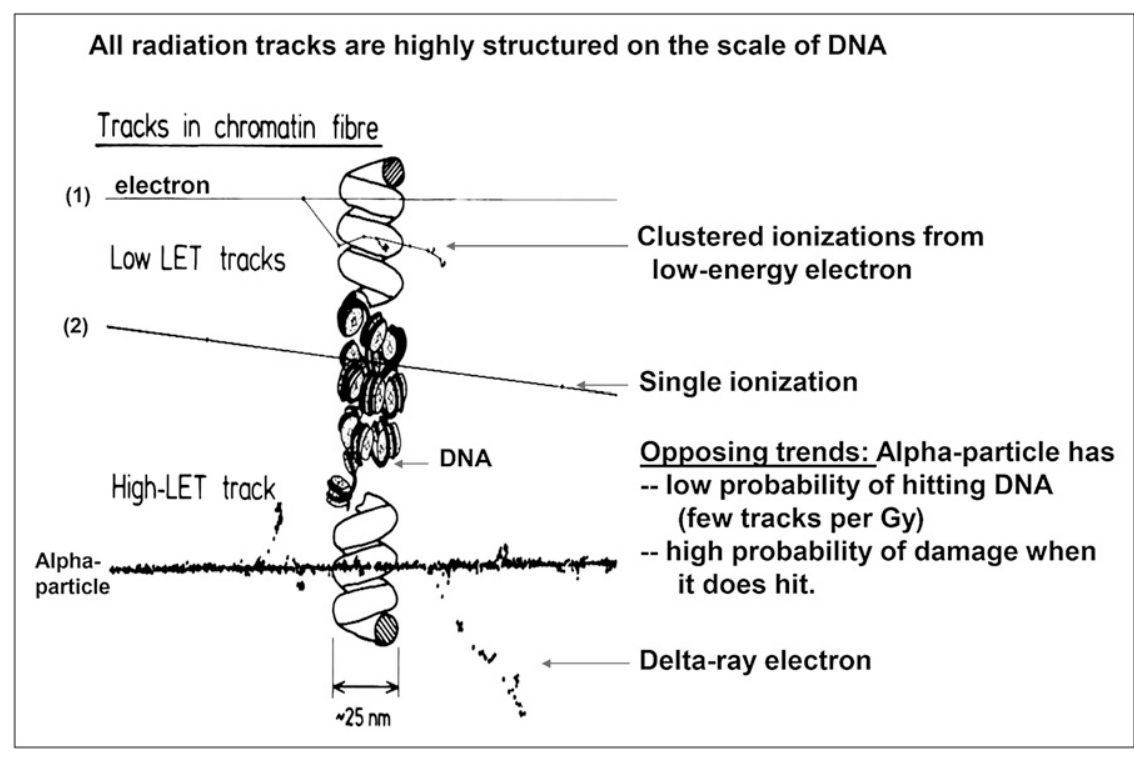

FIGURE 1. Illustration of difference in ionization density between low- and high-LET tracks. (Reprinted with permission of (153).)
Therapeutic nuclear medicine is already a highly multidisciplinary field. Therapy with $\alpha$-particle emitters is easily one of the more multidisciplinary endeavors within this enterprise. This review is intended to provide the necessary background including the physics and dosimetry perspective to aid in the design, conduct, and analysis of clinical trials using $\alpha$-emitting radiotherapeutics.

\section{$\alpha$-PARTICLE RADIOBIOLOGY}

Interest in $\alpha$-particle-emitting radionuclides for cancer therapy is driven by the physical and radiobiologic properties of $\alpha$-particles as compared with those of photons and electrons (Fig. 1). The energy deposited along the path of an $\alpha$-particle per unit path length is shown in Figure 2. As shown in the figure, the energy deposition along the path, or linear energy transfer (LET), of an $\alpha$-particle can be 2 or 3 orders of magnitude greater than the LET of $\beta$-particles emitted by radionuclides such as ${ }^{131} \mathrm{I}$ and ${ }^{90} \mathrm{Y}$.

One of the first studies demonstrating the biologic effects of heavy charged particles was by Raymond Zirkle in 1932 (22). He examined the effect of polonium $\alpha$-particles on cell division in fern spores and showed a much greater biologic effect when the spore nucleus was placed in the Bragg peak of the $\alpha$-particle track, compared with the plateau region of the track (23). Much of the subsequent radiobiology of $\alpha$-particles was established in a series of seminal studies performed by Barendsen et al. in the 1960s (24-32). These studies first demonstrated the now familiar and accepted features of $\alpha$-particle irradiation. A subsequent series of studies on the mutation and inactivation

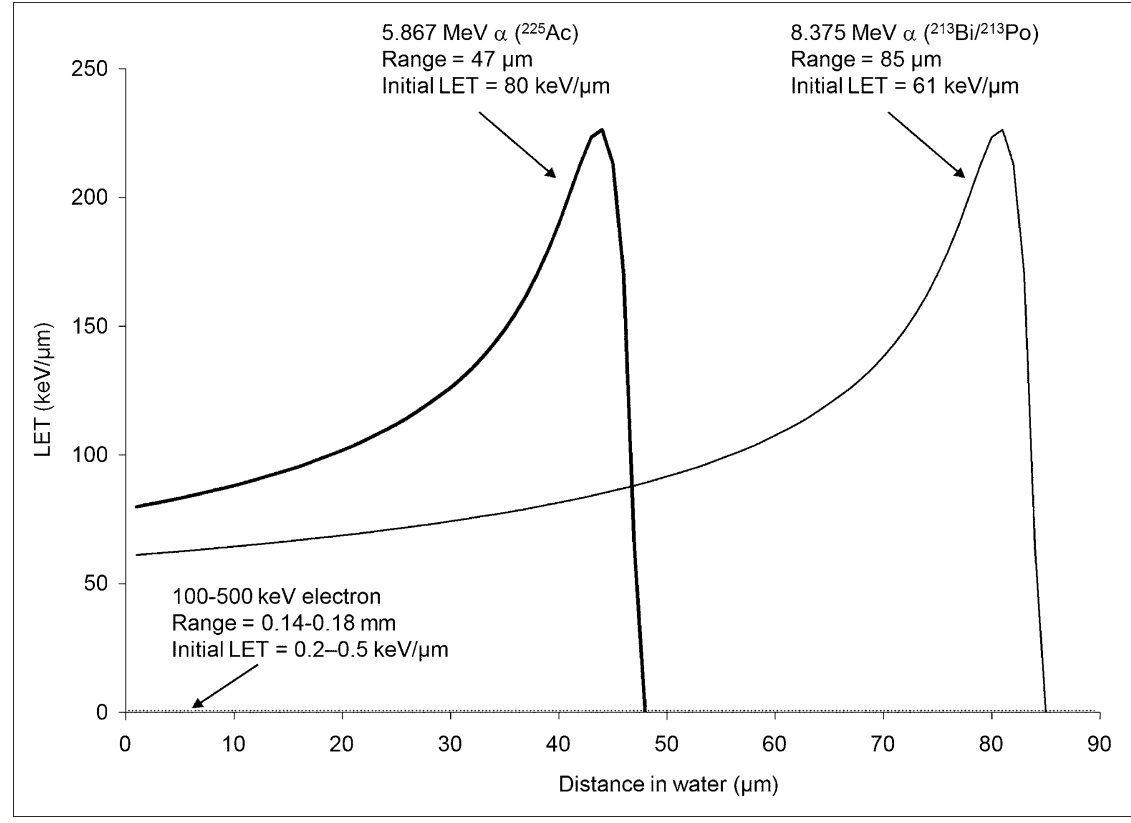

FIGURE 2. LET vs. distance traveled in tissue for $\alpha$-particles with 2 different initial kinetic energies. $\alpha$-Particles emitted with lower initial energy are closer to their Bragg peak and, therefore, start out with higher LET. LET of electrons with initial energy of $100-500 \mathrm{keV}$ is also shown at bottom of plot for comparison. (Plot generated using data from (108).) 
of 3 different mammalian cell types exposed to helium, boron, or nitrogen ions spanning LET values in the range of $20-470 \mathrm{keV} \cdot \mu \mathrm{m}^{-1}$ was key in evaluating the various biophysical models that had been posited to explain lowversus high-LET effects (33-36). The work was also instrumental in providing both the experimental results and the biophysical analysis to help understand the RBEversus-LET relationship established by Barendsen. The biophysical analysis in the last paper of the series (33) provided compelling theoretic support for the concept of 2 types of radiation-induced cellular inactivation. The first type is that due to the accumulation of multiple events that can be repaired at low doses (i.e., sublethal damage) but that saturate the cellular repair mechanisms at higher doses. This type of inactivation yields the characteristic linearquadratic dose-response curve for low-LET radiation, corresponding to a small number, approximately 3-9 (i.e., $\sim 100-300 \mathrm{eV}$ ) ionizations in a distance of about $3 \mathrm{~nm}$ associated with a low probability of producing lethal lesions. The second type of inactivation arises from a single lethal event for high-LET radiation. In this case, a larger number of ionizations, more than 10 , over the 3-nm distance depositing more than $300 \mathrm{eV}$ produces lethal lesions with a high probability. It is important, however, to remember that these studies were performed using external beams of $\alpha$-particles in which the incident $\alpha$-particles were generally orthogonal to an $\alpha$-permeable surface on which the cells were cultured as a monolayer of adherent cells.

As initially demonstrated experimentally by Fisher et al. (37), and then theoretically by Humm et al. (38), and most recently by Kvinnsland et al. (39), the spatial distribution of $\alpha$-particle emitters has an important impact on the absorbed dose distribution and, correspondingly, on the slope of the cell-survival curve. Neti and Howell recently provided experimental evidence of a lognormal cellular uptake of ${ }^{210} \mathrm{Po}$ citrate among a cell population uniformly exposed to the radiochemical and showed that this distribution can substantially alter the cell survival curve (40). Although many of the results obtained from the external-beam studies (summarized in Table 2) are generally applicable regardless of the $\alpha$-particle distribution, specific parameters such as the average number of $\alpha$-particle traversals to induce a lethal event or the $D_{0}$ value (i.e., the absorbed dose required to reduce cell survival to 0.37 ) are highly sensitive to experimental factors such as the geometry of the cells, the thickness or diameter of the cell nucleus, the distribution of DNA within the nucleus (i.e., the phase of the cell cycle), and the number and spatial distribution of the $\alpha$-particle sources relative to the target nuclei.

The distinction between DNA double-strand breaks (DSBs) caused by a single high-LET track versus DNA damage caused by multiple low-LET tracks is illustrated in Figure 3. This basic observation underpins almost all the radiobiology of $\alpha$-particles.
TABLE 2. $\alpha$-Particle Beam Findings That Are Also

Applicable to Internally Administered $\alpha$-Particle Emitters
No.

1

3

absorbed doses

$5 \quad$ Monoexponential surviving fraction curve after uniform irradiation (absence of a shoulder)

\section{Traversals Required for Cell Kill}

The average number of $\alpha$-particle nuclear traversals required to kill a cell, as measured by loss of the subsequent ability to form a colony, ranges from as low as 1 (41) to as high as 20 (42). If bystander effects are included, the lower end of the range would include 0 . The variability in this value when bystander effects are not considered arises because of the high sensitivity of this determination to the geometry of the cell and the nucleus during irradiation and also the LET of the incident $\alpha$-particles and the LET distribution within the nucleus.

Quoting from a publication of Raju et al. (43), "The notion that a cell will be inactivated by the passage of a single $\alpha$ particle through a cell nucleus prevailed until Lloyd and her associates (42) demonstrated that 10 to 20 $5.6 \mathrm{MeV} \alpha$ particles were required to induce one lethal lesion in flattened C3H 10T1/2 cells. Studies by Bird, et al. (44) showed that approximately four ${ }^{3} \mathrm{He}$ ions were required to pass through the cell nucleus to induce one lethal lesion in V79 cells at the $\mathrm{G}_{1} / \mathrm{S}$-phase border, cells in late $\mathrm{S}$ phase required five to eight ${ }^{3} \mathrm{He}$ ions. Todd, et al. (45) investigated the effect of $3.5 \mathrm{MeV} \alpha$ particles on synchronized T-1 cells, and observed that approximately one $\alpha$ particle out of four to five traversing a cell nucleus is effective in inducing one lethal lesion. Roberts and Goodhead (46) estimated that one out of six $3.2 \mathrm{MeV}$ $\alpha$-particle traversals through a C3H 10T1/2 cell nucleus is lethal. Barendsen (47) concluded that the probability of inactivation per unit track length of high-LET $\alpha$ particles is approximately $0.08 \mu \mathrm{m}^{-1}$ for both T-1 and C3H 10T1/ 2 cells consistent with the results of Roberts and Goodhead for C3H10T1/2 cells (46)." In a study comparing high-LET effects of Auger versus $\alpha$-particle emitters, Howell et al. found that about 9 decays of ${ }^{210} \mathrm{Po}$ were required to reduce cell survival to $37 \%\left(\mathrm{D}_{0}\right)$ when it was distributed between the cytoplasm and nucleus of V79 cells; the energy deposited in the cell nucleus corresponds to about 2 complete (maximum chord length) traversals of the cell nucleus (48). In a murine lymphoma cell line, approximately 25 cell-bound $\alpha$-particle-emitting ${ }^{212} \mathrm{~B}$ immunoconjugates were required to reduce clonogenic 


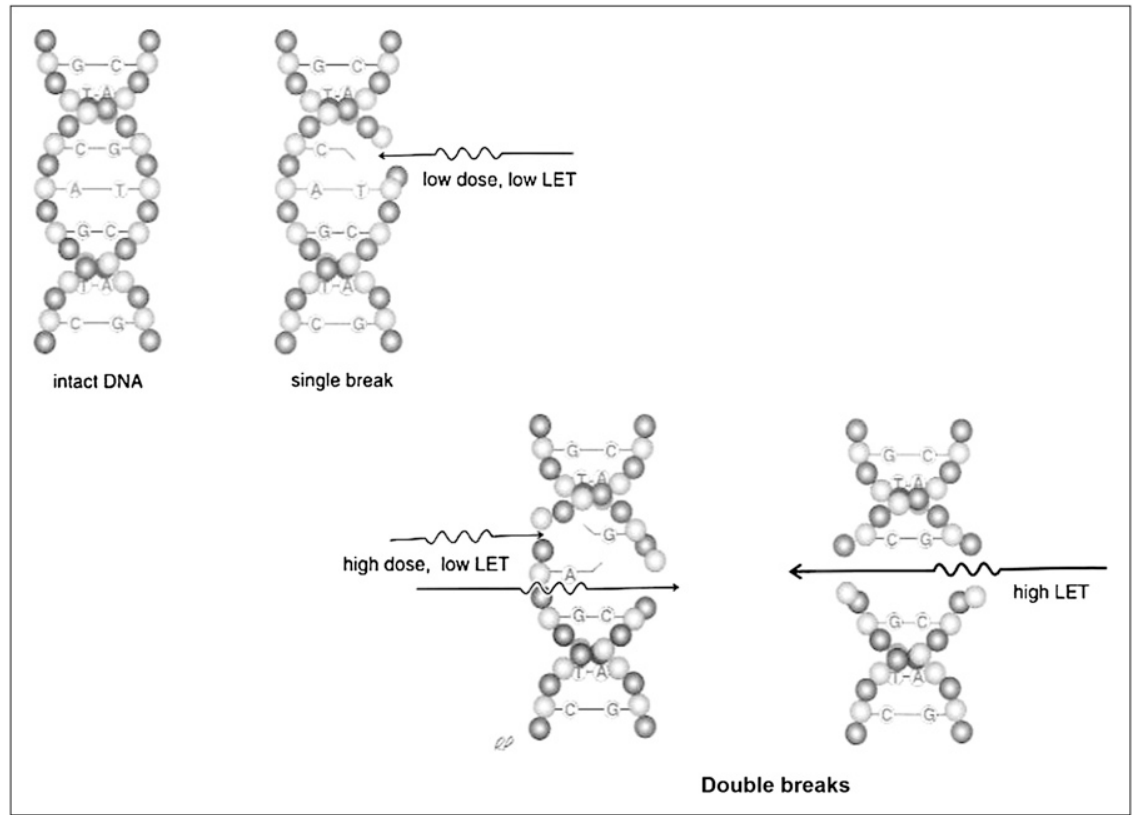

FIGURE 3. Single high-LET track has high probability of yielding DNA DSB, whereas probability of DSB induction with low-LET tracks becomes comparable only at higher absorbed doses. (Reprinted with permission of (154).) survival by $90 \%$ (49). The theoretic efficiency of DSB production when an $\alpha$-particle passes through DNA was examined by Charlton et al. (50) and was found to be surprisingly low; approximately one eighth of $10-\mathrm{MeV}$ $\alpha$-particles passing through a 54-nucleotide section of DNA produce a DSB. One passage in 4 of $1.2 \mathrm{MeV}$ $\alpha$-particles produces a DSB.

Barendsen's estimate of the inactivation probability per unit track length and Goodhead et al.'s determination of the number of lethal lesions per micrometer track through the nucleus (33) suggest another approach for estimating inactivation probability. Along these lines, Charlton and Turner introduced the total $\alpha$-particle path length (or chord length) through the nucleus as a useful parameter (51). This was used to derive $\lambda$, the mean free path between lethal events for $\alpha$-particles traveling through nuclei. Drawing from an extensive compilation of experimental data, the investigators found that this parameter ranged from 1.5 to $64.4 \mu \mathrm{m}$. As expected, $\lambda$ was found to be dependent on the LET (Fig. 4). An inactivation probability per unit track length through the nucleus has also been used in a model describing radiation-induced cellular inactivation and transformation. By incorporating aspects of a state vector model for carcinogenesis (52) into the inactivation/transformation model, Crawford-Brown and Hofmann (53) have described a model that successfully predicts both cell survival and transformation after irradiation by $\alpha$-particles of different LETs at absorbed doses below $1 \mathrm{~Gy}$. This model was used to examine the impact on model predictions of including a correlation between initiation of cellular transformation and cellular inactivation. At absorbed doses greater than $1 \mathrm{~Gy}$, a significant difference was observed in the predicted probability that a cell is transformed and survives.

\section{Cell Survival Curve}

Cell survival curves (i.e., surviving fraction, SF, vs. absorbed dose, D) for low-LET radiation such as X-rays exhibit an initial "shoulder" that is thought to reflect the repair of radiation damage. This type of cell survival curve can be represented by the linear-quadratic equation

$$
\mathrm{SF}=\mathrm{e}^{-\alpha \mathrm{D}-\beta \mathrm{D}^{2}}
$$

The parameters $\alpha$ and $\beta$ are, respectively, sensitivity per unit dose (D) and per unit dose squared $\left(D^{2}\right)$. As the absorbed dose exceeds a certain threshold level, presumably

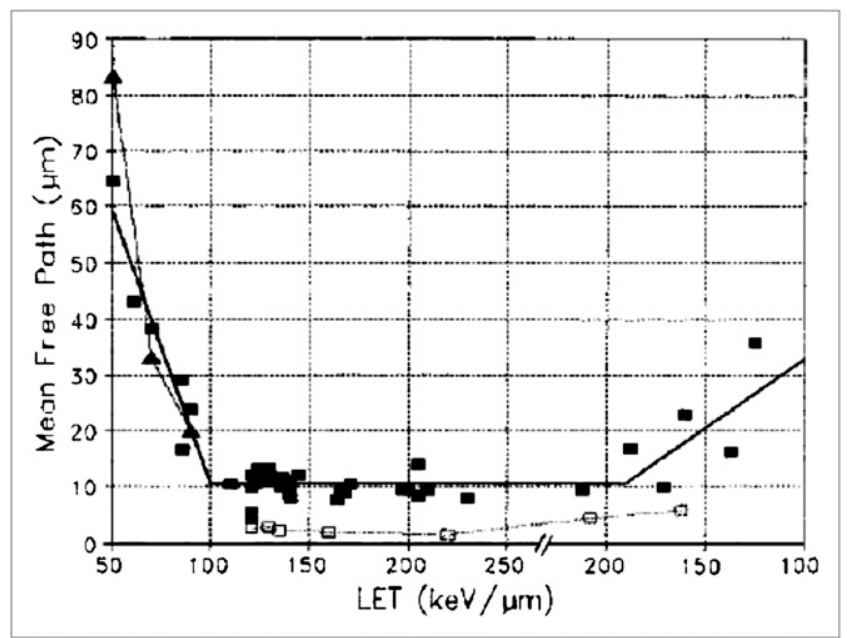

FIGURE 4. Dependence of mean free path on LET. LET is plotted (e.g., from 200 to $100 \mathrm{keV} / \mu \mathrm{m}$ after $250 \mathrm{keV} / \mu \mathrm{m}$ ) so that stopping powers on low-energy side of Bragg peak can be identified. (Reprinted with permission of (51).) 
FIGURE 5. Survival curves obtained with ${ }^{210} \mathrm{Po} \alpha$-particles (1-4) or $250-\mathrm{kVp}$ $\mathrm{x}$-rays (5-8) and with different cell lines: $R_{1}$ cells derived from rhabdomyosarcoma of rat (1 and 8 ), subline of human kidney cell line $T_{1}$ with mean chromosome number of 121 (2 and 5), subline of $\mathrm{T}_{1}$ with 62 chromosomes ( 3 and 6 ), and subline of $T_{1}$ with 63 chromosomes (4 and 7). (Adapted from (155).)

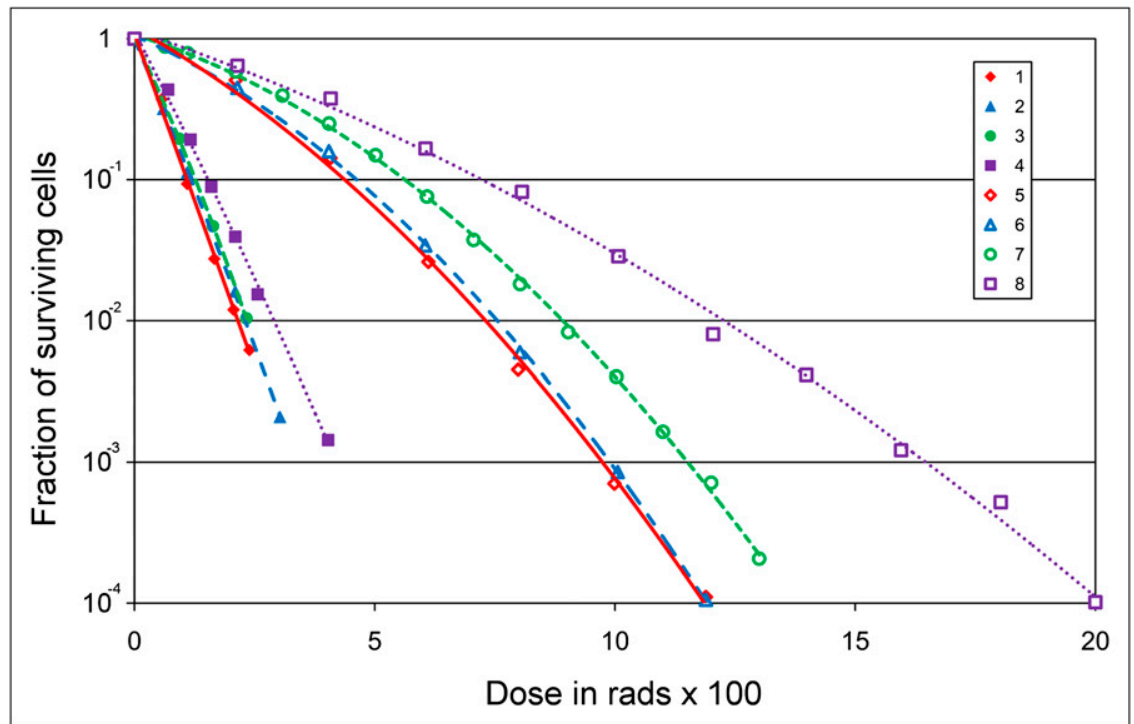

the dose at which the radiation damage repair rate is reduced relative to the rate of induced damage, the relationship between surviving fraction and absorbed dose approaches log-linearity. As shown in Figure 5, the cell survival curve for $\alpha$-particle radiation is log-linear at low as well as high absorbed doses; that is, it does not exhibit a shoulder region, reflecting the reduced capability of cells to repair $\alpha$-particle damage. The equation describing this is

$$
\mathrm{SF}=\mathrm{e}^{-\mathrm{D} / \mathrm{D}_{0}},
$$

with the parameter $D_{0}$ equal to the absorbed dose required to yield a surviving fraction of $37 \%$. The log-linear aspect of cell survival curves after $\alpha$-particle irradiation reflects a reduced repair capacity, not the absence of repair. That $\alpha$-particle damage is repaired has been demonstrated by several studies, as described in the "Radiomodulation" section. Repair of damage is not inconsistent with singleevent lethality and a log-linear survival curve. The key distinction is whether death is a result of accumulated damage or of a single event. Cell survival curves that exhibit an initial shoulder reflect cell death that results from the accumulation of damage, whereas log-linear cell survival curves reflect cell death arising from a single event, without the need to accumulate damage. In both situations, repair is possible.

\section{Oxygen Effect}

In addition to dose rate, the influence of oxygen concentration has long been recognized as an important factor in the response of cells to radiation $(54,55)$. Figure 6 demonstrates that this effect is strongly influenced by the LET of the radiation. The oxygen enhancement ratio (OER), or relative radiosensitivity of cells to oxygen concentration, is 1 for charged particles with an LET greater than $140 \mathrm{keV} / \mu \mathrm{m}$ (24). The initial LET of 4- to $8-\mathrm{MeV} \alpha$-particles typical of the $\alpha$-emitters of interest in targeted $\alpha$-emitter therapy ranges from 110 to $61 \mathrm{keV} / \mu \mathrm{m}$. The OER values in this LET range are 1.3 to 2.1. Because the LET of the emitted $\alpha$-particles increases well beyond the $140 \mathrm{keV} / \mu \mathrm{m}$ threshold for OER $=1$ as the Bragg peak is approached, the ability of $\alpha$-particles to overcome radioresistance due to hypoxia will depend on the spatial distribution of the $\alpha$-emitters relative to the hypoxic region. The ability to overcome hypoxia, noted above, is strictly radiobiologic. There are studies suggesting that hypoxia may alter the phenotype of the cell via cell signaling pathways associated with increased concentrations of hypoxia-inducible factor $1 \alpha$, leading to a cell phenotype that is inherently more resistant to radiation and other cytototoxic agents, including chemotherapeutics (56). The classic OER effect has been explained as a free radicalmediated effect in which the presence of oxygen "fixes" free radical-induced damage, thereby making repair of the damage more difficult (57). In this case, the reduced OER effect with $\alpha$-particle radiation may be explained by the

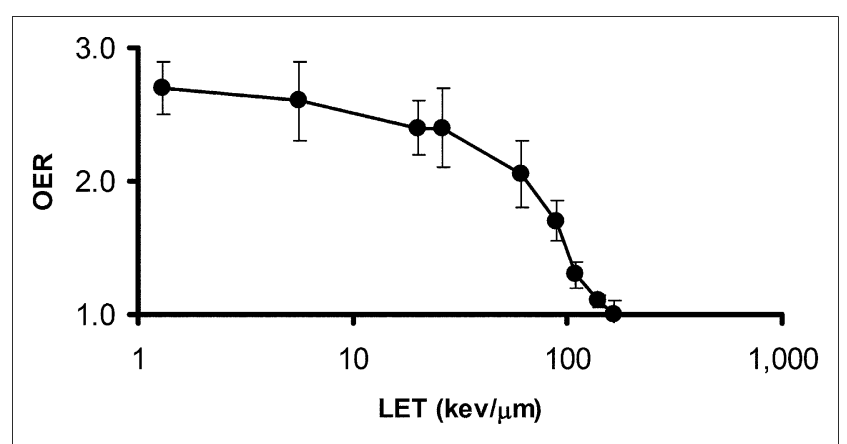

FIGURE 6. OER as function of LET. OER was measured using cultured human kidney-derived cells incubated in air or nitrogen. $\alpha$-Particles of different energies generated by cyclotron or $250-\mathrm{kVp}$ x-rays (average LET $\approx 1.3 \mathrm{keV} / \mu \mathrm{m}$ ) were used. (Data replotted from (24).) 
preponderance of oxygen-independent direct DNA damage (vs. oxygen-dependent indirect, i.e., free radical-mediated, DNA damage) characteristic of $\alpha$-particles.

\section{Dose Rate}

The influence of absorbed dose rate on cell survival for low-LET emissions is well established. As the dose rate is lowered and the exposure time extended, the biologic effect of a given dose is generally reduced (58). The primary explanation for this effect is that lower dose rates provide a greater time interval for DNA damage repair. Because high-LET damage is not easily repaired, dose rate or even dose fractionation should not impact cellular survival. Barendsen examined changes in survival after $\alpha$-particle irradiation over a dose-rate range of $0.5-100 \mathrm{rad} / \mathrm{min}$, and no dose-rate effect was observed (26).

\section{Oncogenesis}

Although not of prime concern in cancer therapy, a much higher incidence of cancer induction is associated with $\alpha$-particle irradiation (59). Accordingly, the radiation weighting factor for $\alpha$-particles is 20 , meaning that a committee review of the relevant experimental and human data has determined that per unit absorbed dose, $\alpha$-particles are associated with a 20 -fold greater risk of cancer induction than is a similar absorbed dose of photons or $\beta$-particles (60). A review of human and animal data related to cancer risk estimates has called the value of 20 into question for bone cancer and leukemia risk, particularly at low absorbed doses (61). Consideration of dose to target cells on bone surfaces as opposed to the average bone dose gives an RBE for bone cancer risk of 3-12. The authors (61) noted that these estimates may also change since there is evidence that bone cancer risk may be best assessed by calculating dose to a 50- $\mu \mathrm{m}$ layer of marrow adjacent to the endosteal bone surface as opposed to a single $10-\mu \mathrm{m}$ layer as currently assumed. Likewise, a factor of 2 to 3 is more consistent with the experimental data for leukemia induction. All these estimates are based on $\alpha$-particle emitters not projected for use in targeted $\alpha$-emitter therapy. The few studies that have been performed to examine carcinogenesis of the short-lived $\alpha$-emitters of interest in targeted $\alpha$-emitter therapy have used ${ }^{211}$ At. Neoplastic changes, predominately papillary carcinomas in various organs, were seen in a few animals but not more than what was expected for untreated mice. Brown and Mitchell (62) reported a 13\% incidence of plasmocytoma in tumor-bearing mice of the same strain 13-21 mo after treatment with $200-750 \mathrm{kBq}$ of 6-211 At-astato-2-methyl-1,4-naphthoquinol bis(diphosphate salt). The frequency of low-grade B-cell non-Hodgkin lymphoma was high but similar to that of the control population. A high incidence of pituitary adenomas and mammary tumors has been seen in rats treated with ${ }^{211} \mathrm{At}$ $(63,64)$. These tumors, however, were partially attributed to secondary effects associated with a hormonal imbalance resulting from thyroid or ovarian tissue compromise.

\section{Fractionation}

The fundamental rationale for fractionation in externalbeam radiotherapy is based on the differential repair capacity of most normal organs compared with most tumors. This is expressed in terms of early versus late responding tissues, corresponding to high versus low $\alpha / \beta$ ratios (65). Fractionation tends to spare normal organs without a reduced efficacy against tumors. As shown in Figure 7, this is not the case with high-LET radiation (26). Cultured cells derived from human kidneys showed the same surviving fraction for a single total absorbed dose of $\alpha$-particle radiation or the same total dose delivered in 2 equal fractions, separated by $12 \mathrm{~h}$. For the same cell line, similar results have been observed when the total dose was delivered in 3 equal fractions at 4, 8, and $12 \mathrm{~h}$ after cell plating (25). Extension of the biologically effective dose formalism to account for RBE effects has also demonstrated that fractionation is theoretically not likely to confer a normal tissue-sparing effect for high-LET radiation (66). Similar conclusions may be drawn for the chronic, exponentially decreasing dose rates delivered by internally administered $\alpha$-particle emitters.

\section{Radiomodulation}

Few examples of agents that can modulate $\alpha$-particle radiation-induced damage have been reported. In the early 1960s, Barendsen et al. compared the radioprotective effects of cysteamine and glycerol (25). The surviving fraction of $\mathrm{T}_{1}$ (human kidney-derived) cells increased by a factor of 3.7 for $250-\mathrm{kVp}$ x-irradiation and only 1.2 for

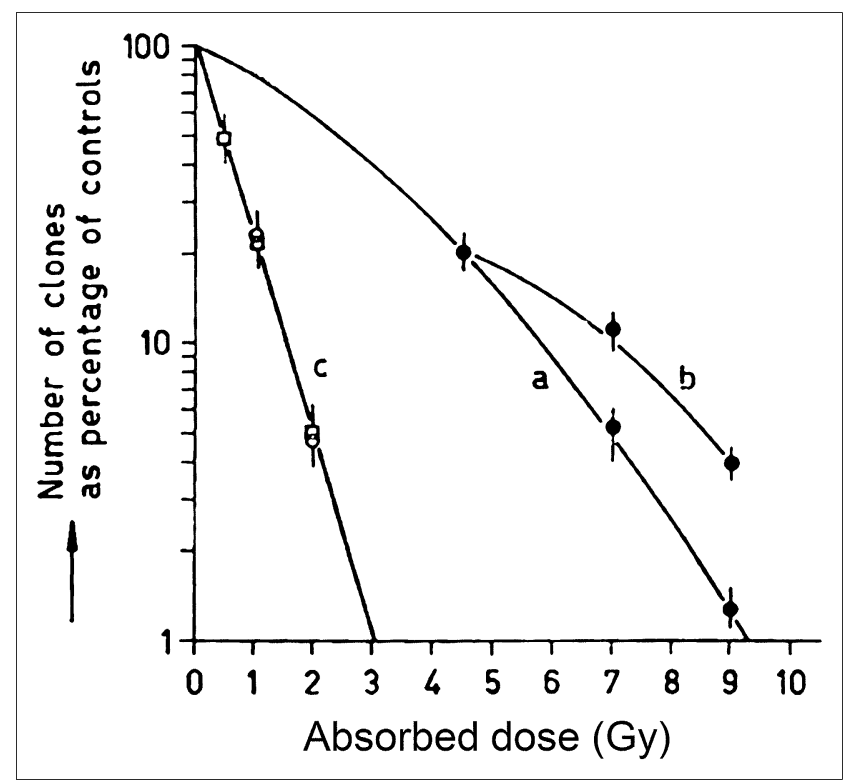

FIGURE 7. Effect of fractionation on cell survival: cell survival curve obtained with single doses of 200-kV x-rays (a), curve obtained when 200-kV x-ray doses are separated by $12 \mathrm{~h}$ ( $4.5 \mathrm{~Gy}$, then 2.5 or $4.5 \mathrm{~Gy}$ ) (b), and curve obtained with 3.4-MeV $\alpha$-particles (c). In (c), circles correspond to single exposure, and squares to 2 equal exposures separated by 12 h. (Adapted from (26).) 
${ }^{210} \mathrm{Po} \alpha$-particle radiation. Similar results were observed with glycerol; cell survival was increased by 2.0 and 1.2 for 250-kVp x-rays and ${ }^{210}$ Po $\alpha$-particles, respectively. Qualitatively consistent but quantitatively different results have been obtained with the radiosensitizer Wortmannin. This irreversible and potent inhibitor of DNA-dependent protein kinase is involved in the nonhomologous end-joining DNA repair pathway invoked in the repair of DNA DSBs (67). In V79 Chinese hamster cells, Wortmannin led to a 3- to 4-fold increase in genotoxic damage, as measured by the induction of micronuclei. High-LET irradiation, as delivered by a boron neutron-capture reaction, leading to the release of $\alpha$-particles with an average energy of $2.3 \mathrm{MeV}$, yielded an increase in micronucleus induction of approximately 2-fold. This finding suggests that the more complex double-strand damage induced by high-LET radiation is a substrate of the nonhomologous end-joining pathway $(68,69)$. In vivo studies in mouse testes have shown that soybean oil, $S$-(2-aminoethyl)isothiuronium bromide hydrobromide, and cysteamine afford some protection against the cytotoxic effects of 5.3-MeV $\alpha$-particles emitted by ${ }^{210} \mathrm{Po}(70-73)$. When spermatogonial cell survival was used as the biologic endpoint, dose modification factors of 2.2, 2.4, and 2.6, respectively, were obtained. No modification of the spermatogonial response to $\alpha$-particles was observed when dimethyl sulfoxide or vitamin $\mathrm{C}$ was used $(74,75)$.

That DNA damage and its repair are at the core of $\alpha$-emitter radiobiologic effects is supported by many years of experimental and theoretic work. It is important, however, to keep in mind that all the foundation work regarding the radiobiology of $\alpha$-emitters was performed well before modern molecular biology came into existence. In light of the remarkable and far-reaching gains in our understanding of the molecular mechanisms involved in cancer genesis, the cellular response to radiation, and DNA single and DSB repair, a reexamination of $\alpha$-particle radiobiology using modern tools is warranted.

\section{RBE}

The biologic effect of ionizing radiation is influenced by the absorbed dose, the dose rate, and the quality of radiation. Radiation quality is characterized by the spatial distribution of the energy imparted and by the density of ionizations per unit path length, referred to as the LET or stopping power of a charged particle $(22,60)$. Depending on the effect considered, greater ionization density along a track will increase the probability of inducing a biologic effect. Compared with electrons and $\beta$-particles, $\alpha$-particles exhibit a high density of ionization events along their track (76). Electrons and $\beta$-particles that are emitted by radionuclides generally range in energy from several megaelectron volts to as low as several kiloelectron volts, with corresponding LET values ranging from about 0.1 to $1 \mathrm{keV} / \mu \mathrm{m}$ ( $\beta$-particles actually are characterized by a spectrum of energies; the bottom end of the spectrum is zero). The exception to these is Auger electrons, which have energies as low as several electron volts and corresponding LET values as high as $25 \mathrm{keV} / \mu \mathrm{m}$. $\alpha$-Particles emitted by radionuclides range in energy from 2 to $10 \mathrm{MeV}$, with initial LET values ranging from 60 to $110 \mathrm{keV} / \mu \mathrm{m}$. A given tissue-absorbed dose resulting from $\alpha$-particles, therefore, is likely to yield considerably greater biologic effects (again depending on the effect being considered) than the same absorbed dose delivered by typical electrons or $\beta$-particles. To account for differences in energy deposition pattern exhibited by different quality radiations, the concept of RBE has been established. An authoritative review of this concept, its derivation, and appropriate application has been published by the International Commission on Radiological Protection (ICRP) $(60,77)$, and the reader is encouraged to consult this source for additional information. In radiobiology, RBE equals the ratio of absorbed doses of 2 types of radiation that produce the same specified biologic effect.

\section{RBE Defined}

RBE is calculated as the absorbed dose of a reference radiation (e.g., x-rays, $\gamma$-rays, $\beta$-particles), $D_{r}(x)$, required to produce a biologic effect, $\mathrm{x}$, divided by the absorbed dose of the test radiation, $\mathrm{D}_{\mathrm{t}}(\mathrm{x})$, required to produce the same biologic effect:

$$
\operatorname{RBE}(\mathrm{x})=\frac{\mathrm{D}_{\mathrm{r}}(\mathrm{x})}{\mathrm{D}_{\mathrm{t}}(\mathrm{x})}
$$

RBE is thus an experimentally determined value defined for a particular biologic effect and therefore for a particular biologic system.

The experimentally determined value can be influenced by the variability of the biologic system across different laboratories. This issue has been examined for studies in vitro (78). The methodology used for calculating the absorbed dose of the 2 radiation types will also impact the result. Ideally, this should not be the case. The methodology used should provide the true absorbed dose value or specific energy distribution ("Case for Microdosimetry" section) to the relevant biologic target for both the test and the reference radiations. In practice, however, this is a challenge even for studies in vitro (79). In the setting of human $\alpha$-particle emitter dosimetry, consistency and reproducibility will be as important as accuracy. This issue is discussed in greater detail in "Recommendations for Dosimetry of Deterministic Effects" section.

The fact that the RBE is related to the pattern of ionizing energy deposition along a particle track leads to a third factor that will impact the results. The RBE for a particular radiation type will also depend on the initial emission energy of the particle (i.e., how close the particle is to the end of its track [the Bragg peak]). This factor has been examined by Charlton et al. (80) and Howell et al. (81). In the studies by Howell et al., a uniform distribution of decays was assumed to calculate the $\mathrm{D}_{0}$ for $7 \alpha$-emitting 
isotopes covering a wide range of initial energies. Using the $\mathrm{D}_{0}$ obtained for $\mathrm{X}$-rays for the cell line used in the $\alpha$-emitter calculations, a linear relationship between RBE and initial $\alpha$-particle energy was obtained over an initial $\alpha$-energy ranging from 5 to $8.5 \mathrm{MeV}$. The straight line was given by $\mathrm{RBE}=2.9-0.167 \mathrm{E}_{\mathrm{i}}$, where $\mathrm{E}_{\mathrm{i}}$ is the initial $\alpha$-particle energy in megaelectron volts. This is an approximate scaling of the equation derived from in vivo experimental data by Howell et al. (81). In addition to effects related to the Bragg peak, nonuniform biodistribution of the $\alpha$-emitters also leads to microdosimetric effects that impact RBE and the slope of the cell-survival curve (37-39).

If the reference radiation yields a dose-response relationship that is not log-linear for the biologic system examined, the RBE value will depend on the specific biologic quantitative endpoint selected (e.g., $\mathrm{D}_{50}, \mathrm{D}_{37}(=$ $\left.\mathrm{D}_{0}\right), \mathrm{D}_{10}$, etc., which determines whether the comparison falls in the shoulder or in the log-linear region of a doseresponse or survival curve). The type of biologic endpoint (e.g., survival, mutation) and the dose rates of the test and reference radiations will also influence the RBE value. Strictly speaking, the test radiation should be delivered in a manner identical to that of the reference radiation (e.g., chronic or acute). However, acute externally administered $\mathrm{X}$ - and $\gamma$-rays are often used as the reference radiation when RBE values are determined for internally administered radionuclides. Given the often-sizeable difference in biologic responses to acute-versus-chronic low-LET radiation, the dose rate at which the reference radiation is delivered can impact the resulting RBE (48). The dose-rate pattern delivered by radiopharmaceuticals is generally well represented by multicomponent exponential functions. Howell et al. have delivered such patterns with external beams of ${ }^{137} \mathrm{Cs} \gamma$-rays (82). This approach was used to study the bone marrow response to exponentially decreasing dose rates of ${ }^{137} \mathrm{Cs} \gamma$-rays (83). The response of granulocyte-macrophage colony-forming cells in the marrow to decreasing dose rates with half-times ranging from $62 \mathrm{~h}$ to $\infty$ (i.e., constant dose rate) were studied and compared with the response to acute exposures. Mean lethal doses for chronic irradiation were up to $40 \%$ higher than those for acute exposures. Thus, care must be taken when comparing RBE values based on different reference radiations.

Based on a review of experimental literature, an RBE value of between 3 and 5 was recommended for cell killing by a panel convened by the Department of Energy in 1996 (84). Because human studies using $\alpha$-particle emitters have yet to be analyzed for deterministic effects, an RBE of 5 was recommended for projecting the possible deterministic biologic effects associated with an estimated $\alpha$-particle absorbed dose.

$R B E, Q$, and $w_{R}$

The discussion thus far has focused on RBE. RBE is occasionally confused with quality factors, $Q$, and radiation weighting factors, $w_{R}$. This confusion reflects the historical evolution of RBE which was originally defined as relative biological efficiency and intended to apply to both radiobiology (deterministic effects) and protection (stochastic effects). As currently recommended by the ICRP, however, $\mathrm{RBE}$ is not to be used directly in radiation protection but only as a starting quantity to derive the radiation weighting factor $w_{\mathrm{R}}$, which replaced the quality factor $Q$ in the most recent ICRP recommendations $(85,86)$. The $\mathrm{RBE}$ values used to arrive at $w_{\mathrm{R}}$ relate to stochastic endpoints such as cancer induction, rather than deterministic endpoints such as normal-tissue toxicity and tumor cell sterilization in cancer therapy patients. The ICRP radiation weighting factor for $\alpha$-particles is 20 . This value, intended only for stochastic effects caused by $\alpha$-particle irradiation, is based on animal experiments and from analysis of historical $\alpha$-emitter exposures. In contrast to RBE values, weighting factors are not directly measured values but rather are consensus recommendations of the ICRP (60).

The radiation weighting factor $w_{\mathrm{R}}$ is a unitless factor that converts average absorbed dose (in units of grays) to equivalent dose in an organ or tissue. The SI unit for equivalent dose is referred to by the special name sievert. The sievert is not a unit in the conventional sense but is intended to indicate that the absorbed dose value has been adjusted to reflect a biologic risk that is associated with stochastic effects. Although the sievert is often used in the context of deterministic effects, this use is not strictly correct because the ICRP has stipulated that the sievert should be used only to designate the risk of incurring stochastic biologic effects such as cancer. The ICRP has reported on $R B E$ for deterministic effects $\left(R_{B} E_{M}\right)$, but no special name has been chosen by the ICRP for the product of absorbed dose and a factor such as RBE that specifically reflects similar scaling for a deterministic effect (77).

\section{$\alpha$-PARTICLE DOSIMETRY}

Radiation dosimetry offers a means for standardizing and comparing the efficacy of different radiation-based treatments. It provides a logical basis for understanding the effects that various radiation qualities have on biologic matter. For $\alpha$-particle emitters, accurate dosimetry calculations require knowledge of the activity distribution as a function of time at the cellular and subcellular levels (87). Furthermore, an accurate representation of the geometry at this level is also required. For in vitro experiments (i.e., cell survival studies), the activity distribution is straightforward, consisting of uptake on the surface or within the cell, along with a known fraction in the surrounding solution. In these experiments, the cell and nucleus can be approximated as concentric spheres, the dimensions of which can easily be measured. However, for clinical applications, these idealizations give way to complex activity and tissue geometries. In these cases, modeling the 3-dimensional geometry of a spheroid $(88,89)$ or using microscopic data from tissue biopsy samples (90) can provide information on the target 
geometry. Determining the activity distribution, however, remains difficult. Autoradiography (91) may provide a snapshot of the activity distribution at a single instance in time. However, the determination of the activity as a function of time may require mathematic modeling (92-94) of the carrier molecules as they diffuse through tissue and bind to markers on cell surfaces. Ideally, such modeling should be validated using animal model measurements in vivo.

\section{Case for Microdosimetry}

There are 2 methods for calculating the energy deposited by individual $\alpha$-particles. One method uses the MIRD formalism to calculate the average dose to the target (cell nucleus) for a variety of source compartments (cell surface, cytoplasm, and nucleus). Extensive tables have been produced for various combinations of $\alpha$-particle-emitting radionuclides and cellular geometries $(95,96)$. The basis for using mean absorbed dose is related to the biologic properties of low-LET radiations such that a large number, often several thousands, of statistically independent radiation deposition events in a single cell nucleus is required to induce a demonstrable biologic effect. In such a case, the statistical variation of the energy imparted to different cell nuclei is minimal. In contrast, for high-LET irradiation, such as $\alpha$-particles, the effect of even a single event in the cell nucleus is so great that the mean absorbed dose can be a misleading index of biologic effect. This is due to several reasons. Foremost is that the number of $\alpha$-particles that traverse a cell nucleus is often few, and therefore stochastic variations become important. In addition, the path of the $\alpha$-particle through the cell nucleus is also critical. An $\alpha$-particle that crosses directly through a cell nucleus will deposit a large amount of energy, whereas one that merely grazes the surface will deposit little or no energy. Thus, a second method for $\alpha$-particle dosimetry-microdosimetry-takes into account the stochastic nature of energy deposited in small targets. The fundamental quantities in classic microdosimetry are specific energy (energy per unit mass) and lineal energy (energy per unit path length through the target) (97). Microdosimetry was originally proposed by Rossi (98) to explain the stochastic nature of energy deposited in matter by external ionizing radiation. It has subsequently been adapted to the case of internally deposited $\alpha$-particle emitters (99-101).

\section{Microdosimetric Techniques}

Microdosimetric spectra may be calculated using either analytic or Monte Carlo methods (102). Analytic methods use convolutions (via Fourier transforms) of the singleevent spectrum to calculate multievent distributions (98). The single-event spectrum represents the pattern of specific energy depositions for exactly $1 \alpha$-particle hit. Kellerer developed a method to efficiently determine the multipleevent spectrum through the use of Fourier transforms (103). Although analytic codes are computationally efficient, they are often limited to simple source-target geometries be- cause the single-event spectrum must be known for each source-target configuration. Monte Carlo codes offer greater flexibility than analytic methods and can simulate a wide variety of geometries and source configurations. Idealizations are often made to simplify the coding and reduce calculation time. In nearly all Monte Carlo codes, $\alpha$-particles are assumed to travel in straight lines. This approximation is valid for $\alpha$-particles having energies less than $10 \mathrm{MeV}$ (97). In addition, the range of $\delta$-rays (energetic electrons originating from the $\alpha$-particle track that cause secondary ionizations in the vicinity of the track) and the width of the $\alpha$-particle track $(\sim 100 \mathrm{~nm})$ are often ignored because the targets that are studied (i.e., cell nucleus) are much larger than these dimensions (104). The rate of $\alpha$-particle energy loss is characterized by the stopping power. These data for a variety of media can be obtained from the literature (105-108). Inherent in the stopping-power formulation is the continuous slowingdown approximation. As the name implies, this approximation assumes that $\alpha$-particles lose energy continuously as they traverse matter. Thus, the calculated specific energy imparted depends on the choice of stopping powers used.

\section{Criterion for Adopting Microdosimetry}

The rationale for microdosimetry was outlined by Kellerer and Chmelevsky (109). They suggested that the stochastic variations of energy deposited within the target must be considered when the relative deviation of the local dose exceeds $20 \%$. For example, a small cell nucleus with a diameter of $5 \mu \mathrm{m}$ irradiated by $\alpha$-particles would require an average dose of at least $100 \mathrm{~Gy}$ for the relative deviations to be less than the $20 \%$ threshold. Thus, the necessity for microdosimetric methods will depend on the source distribution, the target size and shape, and the expected mean dose. For small average doses (such as those expected by nontargeted tissues) microdosimetry may be important in characterizing the pattern of energy deposition and in understanding how this pattern relates to clinical outcomes. However, in tumor, where the mean dose may be large, a microdosimetric treatment may not be necessary.

\section{Microdosimetry Implementation Techniques}

Although microdosimetry has increased our understanding of stochastic patterns of energy deposition by $\alpha$-particles in both simple and complex geometries and has made it possible to explain in vitro observations, application to clinical practice has been limited because time-dependent activity distributions at the subcellular level are complex and not well characterized in vivo. Roeske and Stinchcomb (110) described a technique for determining dosimetric parameters that are important in $\alpha$-particle dosimetry. These parameters consist of the average dose, SD of specific energy, and the fraction of cells receiving zero hits. The individual values are determined using tables of the " $\mathrm{S}$ " value (111), and the first and second moments of the single-event spectra. The average dose is determined by 
multiplying the $\mathrm{S}$ value by the cumulated activity within the source compartment. Dividing the average dose by the first moment of the single-event spectrum yields the average number of hits. Subsequently, the fraction of cells receiving zero hits (or any number of hits) can be determined using the average number of hits and the Poisson distribution. The SD is the product of the average number of hits and the second moment of the single-event spectrum. Individual moments may be determined using either analytic methods or Monte Carlo calculations. Stinchcomb and Roeske (112) have produced tables of the $\mathrm{S}$ value and the individual moments for several geometries and source configurations appropriate for $\alpha$-particle therapy. These tables were also used in the analysis of cell survival after $\alpha$-particle irradiation (112).

\section{Applications of Microdosimetry}

Early applications of microdosimetry were performed to assess the probability of cancer induction after exposure to $\alpha$-emitters. These exposures were generally not intended for therapeutic purposes, and carcinogenesis was of concern. In one such application, the specific energy distributions for plutonium oxide in dog lung were calculated. The calculations accounted for the size distribution of the inhaled aerosol and the associated deposition probabilities in the lung for various particle sizes. The distribution of target sites; the probability of an $\alpha$-particle intersecting a target site; and the range, energy loss, straggling characteristics, and $\delta$-ray production of $\alpha$-particle tracks were also considered. The analysis provided an improved understanding of the relationship between dose, as described by microdosimetric specific energy spectra, and response, as measured by the incidence of lung tumors in beagle dogs (113).

In radioimmunotherapy, microdosimetry has been used in several $\alpha$-particle applications. These applications can be broadly characterized as theoretic studies of simple cellular geometries, experimental analysis of cell survival after $\alpha$-particle irradiation, and the microdosimetry of realistic geometries such as multicellular spheroids and bone marrow. The work in each of these categories will be discussed separately.

Roesch (99) described an approach for calculating microdosimetric spectra. Fisher et al. (37) subsequently applied this approach to several geometries that have therapeutic application, including sources distributed on and within individual cells, sources distributed within spheric clusters of cells, and sources located in cylinders (i.e., blood vessels) that deposited energy within spheric cell nuclei a short distance away. These calculations showed the number of $\alpha$-particle emissions originating from cell surfaces that would be needed to inactivate cancer cells with high efficiency. The basic geometries that described the spatial distribution of $\alpha$-emitters relative to the spatial distribution of target spheres have served as the basis of those used in several theoretic studies. In one such study, Humm (114) used a Monte Carlo method with a model of cell survival to estimate the surviving fraction of cells located outside a capillary and cells located within a tumor with uniformly distributed ${ }^{211}$ At. Although the mean dose was similar for these 2 types of geometries, there was a significant variation in the expected cell survival due to the differences in the specific energy spectra. In particular, the fraction of cells receiving no $\alpha$-particle hits increased with distance from the capillary (due to the short range of the $\alpha$-particles). The surviving fraction versus mean specific energy was biexponential. That is, for low doses, the slope of this curve was similar to that of a uniformly irradiated tumor. However, with increasing doses, the curve was less steep and asymptotically approached a value corresponding to the fraction of nonhit cells. Building on the previous analysis, Humm and Chin (38) analyzed how specific energy spectra are affected by cell nucleus size, binding fraction, cell volume fraction, and nonuniform binding. Their results indicated that nonuniform distributions of $\alpha$-particle emitters can result in expected survival curves that deviate significantly from the classic monoexponential curves produced by a uniform, external source of $\alpha$-particles. In these studies, although the inherent cell sensitivity $\left(z_{o}\right)$ was held constant, the slope of the cell survival curve as a function of absorbed dose to the medium was highly dependent on the source configuration. Furthermore, simulations in which cells were more uniformly irradiated resulted in steeper cell survival curves than those in which the distribution of $\alpha$-emitters was highly heterogeneous. The effects of cell size and shape on expected cell survival were further studied by Stinchcomb and Roeske (115). In their analysis, the cell and nucleus were assigned various shapes ranging from spheres to ellipsoids where the ratio of the major-to-minor axis was varied from 1 to 5 while the volume of the nucleus was held constant. Separately, the dimensions of the nucleus were varied while the shape was held constant. Calculations of specific energy spectra and resulting cell survival demonstrated that the expected surviving fraction was not a strong function of the target shape, provided the volume was fixed. However, significant variations in cell survival were observed as the volume of the nucleus was varied. More recently, Aubineau-Laniece et al. developed a Monte Carlo code to simulate cylindric geometries as a model for bronchial airway bifurcations (116). In a series of reports on $\alpha$-particles from radon progeny, Fakir et al. (117-119) demonstrated that for uniform surface emissions, there were significant variations in cellular energy deposition. Larger variations in the hit frequencies and energy deposited were observed when a nonuniform distribution of activity was also considered. Palm et al. (120) examined the microdosimetric effects of daughter products from ${ }^{211} \mathrm{At}$. Separate simulations were performed assuming the daughter products decayed at the site of ${ }^{211} \mathrm{At}$ emission or that they diffused away from the site. Based on an analysis of experimental data, the ${ }^{210} \mathrm{Po}$ daughter product seemed to diffuse from the decay site, decreasing the energy deposited 
in the cell nucleus by a factor of 2 . All these studies illustrate the need to accurately model the source-target geometry. Moreover, approximations, such as using mean values, may impact both the specific-energy spectrum and subsequent calculation of cell survival (39).

\section{Application to Cellular Clusters}

Single-cell survival analyses after $\alpha$-particle irradiation has also been extended to multicellular clusters. Charlton (89) described a multicellular spheroid model and simulated $\alpha$-particle energy deposition events within individual cell nuclei. A cell survival model that takes into account the effects of varying LET (51) was combined with the distribution of $\alpha$-particle tracks throughout cells within the spheroid. Simulating a uniform source distribution (average 1 decay per cell, 50\% cell packing), this analysis demonstrated that cell survival decreased significantly (from $57 \%$ to $37 \%$ ) as the spheroid diameter increased from 75 to $225 \mu \mathrm{m}$. The number of hits per cell also increased in larger spheroids when longer-ranged $\alpha$-particle emitters were considered. Cell survival subsequently decreased from $46 \%$ to $26 \%$ in 200 - $\mu$ m-diameter spheroids as the packing fraction was increased from $40 \%$ to $70 \%$ (also with 1 decay per cell). The decrease in cell survival was due to the increased crossfire dose as the packing fraction was increased. In a separate simulation, the total number of decays per spheroid was kept constant while a small fraction of cells $(20 \%)$ was assumed not to take up any activity. This process simulated the effects of cells that lacked a specific targeting moiety. It is interesting to note that the unlabeled fraction did not significantly alter the expected cell survival. In these studies, the specific energy distribution is highly nonuniform and varies with depth below the spheroid surface. Thus, a single dose or specificenergy distribution is not representative of that through the entire tumor. By combining the specific-energy distribution with cell survival models, it is possible to gain insight into those factors that will influence the therapeutic efficacy of a particular targeting approach. However, most of these cell survival models do not take into account second-order processes such as the bystander effect that may play an important role in modeling cellular clusters and micrometastases. Refinement of these models is currently an active area of research $(121,122)$.

\section{Application to Bone Marrow}

Bone marrow is often the dose-limiting organ in radioimmunotherapy. The dosimetry of bone marrow is difficult because of its complex geometry and the presence of tissue inhomogeneities. Thus, idealized models, as have been used in the previous studies, must be replaced by more realistic geometries. The work to date on estimating specific energy spectra for bone marrow has focused largely on using histologic samples obtained from humans or animal models. Akabani and Zalutsky (90) obtained histologic samples of beagle bone marrow and manually measured chord length distributions. Using a Monte Carlo program, they calculated the single-event specific energy distribution for sources both in the extracellular fluid and on the surface of red marrow cells. These single-event distributions were combined with a model of cell survival. This analysis demonstrated that activity concentrated on the cell surface resulted in significantly greater cell killing than did activity in the extracellular fluid. The effect of LET on the survival of human hematopoietic stem cells in various geometries was studied by Charlton et al. (80). These geometries were determined from human marrow samples obtained from cadavers. Microdosimetric spectra and cell survival were calculated for 3 different source-target geometries: isolated cells labeled on their surfaces, a nontargeted distribution of decays in an extended volume, and nontargeted decays in marrow with $36 \%$ of the marrow volume occupied by fat. Two different radionuclides, ${ }^{149} \mathrm{~Tb}$ and ${ }^{211} \mathrm{At}$, were considered. These simulations indicated that for targeted decays ${ }^{149} \mathrm{~Tb}$ was 5 times more effective than ${ }^{211}$ At when compared on a hit-by-hit basis. This enhancement was due to the lower energy of ${ }^{149} \mathrm{~Tb}$ resulting in a higher LET of the incident $\alpha$-particles. Those authors also concluded that cell survival was a function of the position of the decay relative to the cell nucleus. Using a model similar to that of Charlton et al. (80), Utteridge et al. (123) considered the risk of the development of secondary malignancies (i.e., leukemia) from $\alpha$-particles. This risk may be important in evaluating the future therapeutic application of $\alpha$-particles in patients who have an excellent prognosis. Three $\alpha$-emitting radionuclides were considered on the basis of the relative range (short, medium, and long) of the particle. In this analysis, the authors calculated the fraction of cells that are hit and would survive (as these would potentially cause secondary malignancies). They determined that the lowest fraction occurred for low energies and the highest fraction occurred for the highest-energy $\alpha$-particle emitter.

\section{RECOMMENDATIONS FOR DOSIMETRY OF DETERMINISTIC EFFECTS}

Beyond providing a rational basis for a starting administered activity value for a phase I study, dosimetry has an important role in guiding clinical trial design to help maximize the likelihood of a successful, minimally toxic implementation. This is particularly important because $\alpha$-emitter targeted therapy has the potential to be both highly effective and also quite toxic. Which of these 2 aspects emerges in a therapeutic trial will depend on having an understanding of the physical and biologic factors that impact response and toxicity. It is essential that clinical trials investigating targeted $\alpha$-particle therapy be rationally designed; otherwise, there is the risk that $\alpha$-emitters may be abandoned before they have been properly tested in the clinic.

This increased importance of dosimetric analysis is coupled with a greater difficulty in obtaining the human data necessary to perform dosimetry. In contrast to most 
targeted therapy trials to date, collection of biodistribution data for dosimetry from pretreatment imaging studies will not be possible for most $\alpha$-particle-emitting radionuclides with therapeutic potential. This places a greater emphasis on preclinical studies and extrapolation of results obtained from such studies to the human. Several of the $\alpha$-emitting radiotherapeutics decay to $\alpha$-emitting daughters whose distribution may not be that of the carrier. Aside from understanding the biodistribution and dosimetry of the $\alpha$-emitter-labeled carrier, therefore, the biodistribution and dosimetry of the daughter must also be considered (124-131).

In this section, the focus of the discussion and the recommendations that are made are specific to deterministic effects.

\section{Recommendations}

After stability and radiochemical purity of the radiopharmaceutical have been established and an appropriate target identified, the following progression of studies is proposed. Elements of these recommendations have also been described elsewhere (132-134).

1. Determine cellular targeting kinetics and properties.

A. Determine number of sites per cell and fraction of cells expressing target.

B. Determine distribution of binding sites per cell among the targeted cells.

C. Determine binding and dissociation constants for cell targeting (e.g., antibody affinity).

D. Determine internalization rate and fraction internalized.

E. Determine fate of internalized radionuclide.

F. Determine median lethal dose in targeted versus nontargeted cells.

G. Determine cell-level dosimetry for targeted and nontargeted cells.

2. Perform animal (xenograft or transgenic) model studies.

A. Evaluate maximum tolerated administered activity.

B. Identify likely dose-limiting organs.

C. Collect macroscopic (whole-organ) pharmacokinetics.

D. Collect microscopic (e.g., by autoradiography or optical imaging) biodistribution in dose-limiting organs.

E. Evaluate stability of the radiopharmaceutical in vivo.

F. Evaluate efficacy at maximum tolerated administered activity.

G. Perform cell- and organ-level dosimetry for the animal model.

3. Extrapolate data obtained in steps 1 and 2 to the human to arrive at initial activity for a phase I study.

A. Develop and fit a pharmacokinetic model to data obtained in steps 1 and 2.

B. Replace model parameter values with estimated human values; simulate biodistribution in humans.

C. Use model-derived biodistribution to estimate absorbed dose to dose-limiting organs identified in step $2 \mathrm{~B}$.

4. Assess radiopharmaceutical distribution during the phase I study.
A. Image (if possible).

B. Collect and count blood samples.

C. Collect, count, and autoradiograph biopsy samples (if practical).

If there are concerns (not addressed by animal studies) about possible renal, urinary bladder wall, or gastrointestinal toxicity related to the localization of activity in luminal contents versus the organ wall:

D. Collect and count urine samples.

E. Collect and count fecal samples.

Steps 1-3 are general guidelines. The primary objective is to collect adequate preclinical data so as to have an understanding of the $\alpha$-emitters' likely biodistribution and kinetics in humans. This objective is particularly important because pretherapy patient imaging will not be possible. It is essential that this approach not be seen as mandatory for moving $\alpha$-emitter-labeled radiopharmaceuticals to the clinic; in particular, step 3 may be replaced by a projected conservative (worst-case) scenario analysis or by a direct translation of small-animal pharmacokinetics to the human using standard methods to adjust for differences in body size and organ mass (135). The autoradiography proposed in steps $2 \mathrm{D}$ and $4 \mathrm{C}$ will clearly be subject to the practical constraint of $\alpha$-emitter half-life. For short-lived $\alpha$-emitters, microscopic imaging of fluorescently tagged agents may be a viable alternative to autoradiography in animal models.

Conventional Versus Cell-Level Dosimetry. In most cases, a microdosimetric analysis will not be necessary for targeted therapy applications because the activity level administered and mean absorbed doses to targeted cells are larger than in the cases described here and the resulting stochastic deviation is expected to be substantially less than $20 \%$. In such cases, standard dosimetry methods may be applied $(111,136)$. The standard approach to dosimetry calculations has been described by the MIRD Committee (111). In this formalism, the absorbed dose to a target volume from a source region is given as the total number of disintegrations in the source region multiplied by a factor (the $\mathrm{S}$ value) that provides the absorbed dose to a target volume per disintegration in the source region. The sum of these products across all source regions gives the total absorbed dose to the target. MIRD cellular $\mathrm{S}$ values have been published for cell level dosimetry calculations for situations in which the number of disintegrations in different cellular compartments can be measured or modeled (95). With these $S$ values, the absorbed dose to the nucleus may be calculated from $\alpha$-particle emissions uniformly distributed on the cell surface, in the cytoplasm, or in the nucleus.

Conventional Dosimetry for Organs and Tumors. Estimation of the average absorbed dose to a particular normal organ or tumor volume is based on the assumption that the radioactivity is uniformly distributed in the organ and that 
the energy deposited by the emitted $\alpha$-particles is also distributed uniformly within the organ. With some exceptions (137-141), the cross-organ dose from $\alpha$-particle and electron emissions can be assumed negligible for human organ and tumor dosimetry. Care is required in applying $S$ values for $\alpha$-emitters because $\alpha$-emitters may have multiple decay pathways and multiple radioactive daughters that should be considered. For example, $\mathrm{S}$ values for ${ }^{213} \mathrm{Bi}$ will not include the emissions from the ${ }^{213} \mathrm{Po}$ daughter, which has a $4-\mu$ s half-life and contributes $98 \%$ of the $\alpha$-particles emitted by ${ }^{213} \mathrm{Bi}$ decay (the remaining $2 \%$ come from decay of ${ }^{213} \mathrm{Bi}$ itself). This consideration and also the importance of separately accounting for absorbed dose due to electron and photon emissions from that due to $\alpha$-particles requires that the dosimetry calculations be based on absorbed fraction calculations rather than on $S$ values. The methodology is described by the following equations (presented using the recently published updated MIRD schema) (142):

$$
D_{\alpha}\left(r_{T}, T_{D}\right)=\tilde{A}\left(r_{S}, T_{D}\right) \cdot \frac{\sum_{i} \Delta_{i}^{\alpha} \phi\left(r_{T} \leftarrow r_{S} ; E_{i}^{\alpha}\right)}{M\left(r_{T}\right)},
$$$$
D_{e}\left(r_{T}, T_{D}\right)=\tilde{A}\left(r_{S}, T_{D}\right) \cdot \frac{\sum_{i} \Delta_{i}^{e} \phi\left(r_{T} \leftarrow r_{S} ; E_{i}^{e}\right)}{M\left(r_{T}\right)},
$$$$
D_{p h}\left(r_{T}, T_{D}\right)=\frac{\sum_{r_{S}}\left(\tilde{A}\left(r_{S}, T_{D}\right) \cdot \sum_{i} \Delta_{i}^{p h} \phi\left(r_{T} \leftarrow r_{S} ; E_{i}^{p h}\right)\right)}{M\left(r_{T}\right)},
$$

$$
\begin{aligned}
D_{R B E}\left(r_{T}, T_{D}\right)= & R B E_{\alpha} \cdot D_{\alpha}\left(r_{T}, T_{D}\right)+R B E_{e} \\
& \cdot D_{e}\left(r_{T}, T_{D}\right) \\
& +R B E_{p h} \cdot D_{p h}\left(r_{T}, T_{D}\right),
\end{aligned}
$$

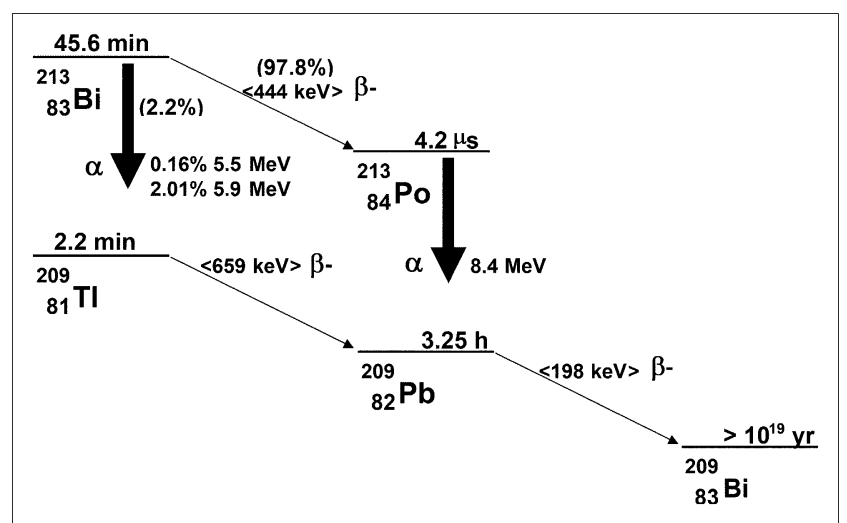

FIGURE 8. Decay scheme for ${ }^{213} \mathrm{Bi}$.

where $D_{x}\left(r_{T}, T_{D}\right)$ is absorbed dose to the target region, $r_{T}$, from emission type $x$, over the dose integration period, $T_{D}$; $D_{R B E}\left(r_{T}, T_{D}\right)$ is RBE-weighted dose to the target region, $r_{T}$; $r_{T}$ and $r_{S}$ are the target and source region (or tissue), respectively; $\tilde{A}\left(r_{T}, T_{D}\right)$ is time-integrated activity or total number of nuclear transitions in the target region, $r_{T} ; M\left(r_{T}\right)$ is the mass of the target region; $\Delta_{i}^{x}$ is mean energy emitted per nuclear transition for the $i$ th emission of particle type $x$ (alpha, electron, or photon); $\phi\left(r_{T} \leftarrow r_{S} ; E_{i}^{X}\right)$ is the fraction of energy emitted per nuclear transition in the source region, $r_{S}$, that is absorbed in the target region, $r_{T}$, by the $i$ th emission of particle type $x$ that is emitted with initial energy $E$; and $R B E_{\alpha}, R B E_{e}$, and $R B E_{p h}$ are RBEs for $\alpha$-particles $(\alpha)$, electrons (e), and photons (ph), respectively $\left(R B E_{e}=R B E_{p h}=1\right)$.

The total number of nuclear transitions in a particular tissue or region is typically obtained by longitudinal imaging, or counting tissue samples for radioactivity. Values for the $\Delta_{i}$ 's are obtained from decay-scheme tabulations published for each radionuclide (143). The absorbed fraction for each decay type, $\phi$, must be calcu-

\begin{tabular}{|c|c|c|c|c|c|c|}
\hline \multirow[b]{2}{*}{ Isotope } & \multicolumn{6}{|c|}{ Electrons } \\
\hline & $\begin{array}{l}\text { Energy } \\
\text { (keV) }\end{array}$ & $\begin{array}{l}\text { Isotope \% per } \\
\text { disintegration }\end{array}$ & $\begin{array}{l}\text { Effective \% per } \\
\text { disintegration }\end{array}$ & $\begin{array}{c}\text { Mean energy } \\
\text { (keV/disintegration) }\end{array}$ & $\Delta^{\mathrm{e}}(\mathrm{Gy}-\mathrm{kg} / \mathrm{Bq}-\mathrm{s})$ & $\begin{array}{l}\text { Electron } \\
\text { range }(\mathrm{mm})\end{array}$ \\
\hline${ }^{213} \mathrm{Bi}$ & 200 & 0.20 & 0.20 & 0.40 & $6.41 \mathrm{E}-17$ & 0.5 \\
\hline${ }^{213} \mathrm{Bi}$ & 347 & 2.55 & 2.55 & 8.85 & $1.42 \mathrm{E}-5$ & 1.4 \\
\hline${ }^{213} \mathrm{Bi}$ & 423 & 0.40 & 0.40 & 1.69 & $2.71 \mathrm{E}-16$ & 1.9 \\
\hline${ }^{213} \mathrm{Bi}(\beta)$ & 444 & 97.80 & 97.80 & 434.23 & $6.96 \mathrm{E}-14$ & 2.1 \\
\hline${ }^{209} \mathrm{TI}(\beta)$ & 659 & 100.00 & 2.20 & 14.50 & $2.32 \mathrm{E}-15$ & 4.2 \\
\hline${ }^{209} \mathrm{~Pb}(\beta)$ & 198 & 100.00 & 100.00 & 198.00 & $3.17 E-14$ & 0.5 \\
\hline Sum & & & & 657.67 & $1.05 E-13$ & \\
\hline
\end{tabular}
lated from tabulations of absorbed fractions for the particular tissue geometry. In almost all cases, non-cell-level dose calculations, the absorbed fractions for $\alpha$-particles,

Mean energy and range values are listed for $\beta$-emissions. Dominant contributors to electron absorbed dose are shown in bold. 
TABLE 4. $\alpha$-Particle Emissions Considered in Absorbed Dose Calculations

\begin{tabular}{|c|c|c|c|c|c|c|}
\hline \multirow[b]{2}{*}{ Isotope } & \multicolumn{6}{|c|}{$\alpha$-Particles } \\
\hline & $\begin{array}{l}\text { Energy } \\
\text { (keV) }\end{array}$ & $\begin{array}{l}\text { Isotope \% per } \\
\text { disintegration }\end{array}$ & $\begin{array}{l}\text { Effective \% per } \\
\text { disintegration }\end{array}$ & $\begin{array}{c}\text { Mean energy } \\
\text { (keV/disintegration) }\end{array}$ & $\Delta^{\alpha}(\mathrm{Gy}-\mathrm{kg} / \mathrm{Bq}-\mathrm{s})$ & $\begin{array}{c}\alpha \text {-range } \\
(\mu \mathrm{m})\end{array}$ \\
\hline${ }^{213} \mathrm{Bi}$ & 5,549 & 0.16 & 0.16 & 8.88 & $1.42 \mathrm{E}-15$ & 42.0 \\
\hline${ }^{213} \mathrm{Bi}$ & 5,869 & 2.01 & 2.01 & 117.97 & $1.89 \mathrm{E}-14$ & 45.5 \\
\hline${ }^{213} \mathrm{Po}$ & 7,614 & 0.003 & 0.003 & 0.22 & $3.58 \mathrm{E}-17$ & 66.0 \\
\hline${ }^{213} \mathrm{Po}$ & 8,375 & 100.00 & 97.80 & $8,190.75$ & $1.31 \mathrm{E}-12$ & 75.6 \\
\hline Sum & & & & $8,317.82$ & $1.33 E-12$ & \\
\hline
\end{tabular}

can be assumed equal to 1 ; the absorbed fractions for electrons are likewise usually assumed equal to 1 . A description of the methods used to calculate these values is beyond the scope of this review but are provided in the references $(141,144,145)$, one of which (141), in particular, describes absorbed fractions that are tabulated by $\alpha$-particle energy for bone marrow trabeculae. For $\alpha$-emitters that decay via a branched decay scheme, as in ${ }^{213} \mathrm{Bi}$, for example (Fig. 8), it is important to account for the relative yield of each branch in determining the total energy emitted by each type of emission (i.e., the $\Delta_{i}$ 's). In the case of ${ }^{213} \mathrm{Bi}$, Tables 3 and 4 summarize the electron and $\alpha$-particle emissions. The tables illustrate how to tally the total electron and $\alpha$-particle energy. As shown, $2.2 \%$ of ${ }^{213} \mathrm{Bi}$ decays results in ${ }^{209} \mathrm{Tl}$ with the emission of an $\alpha$-particle; the initial energy of the emitted $\alpha$-particle is either 5.5 or $5.8 \mathrm{MeV}$, with the probability of each given by the yields shown in Table 2. In the remaining $97.8 \%$ of decays, ${ }^{213} \mathrm{Bi}$ decays to ${ }^{213} \mathrm{Po}$ with the emission of a $\beta$-particle. ${ }^{213} \mathrm{Po}$ itself decays rapidly via the emission of an $8.4-\mathrm{MeV}$ $\alpha$-particle to ${ }^{209} \mathrm{~Pb}$, which in turn decays to ${ }^{209} \mathrm{Bi}$ with the emission of a $198-\mathrm{keV} \beta$-particle. The exercise illustrates that a careful accounting of emissions is required in tallying the energy emitted per disintegration of the administered $\alpha$-emitter, even when the decay scheme is relatively simple as for ${ }^{213} \mathrm{Bi}$. Although outside the scope of this review, the photon $S$ values (Table 5) can be calculated on the basis of tabulations of photon absorbed fractions to different source-target organ combinations and photon energies (146).

\section{Units}

The issue of identifying the most appropriate dosimetry quantities and units is particularly important for $\alpha$-emitters because, as noted earlier, there can be confusion regarding the calculation of dosimetry quantities that relate to stochastic versus deterministic effects. It is incorrect to assign the unit sievert to the quantity defined by Equation 7 . The sievert is not a unit in the conventional sense but, rather, is intended to indicate that the absorbed dose value has been scaled to reflect a biologic risk that is associated with stochastic effects. Although the product of deterministic RBEs and absorbed dose in grays has been referred to as a sievert, this is not strictly correct because sievert should be used only to designate the risk of incurring stochastic biologic effects such as cancer. No special named unit has been widely adopted to reflect a dose value that has been multiplied by an RBE and that specifically reflects the magnitude of deterministic effects. The MIRD Committee has proposed that the barendsen (Bd) be defined as the special named unit for the product of deterministic RBE and absorbed dose and has published a commentary to this effect (147). To avoid confusion during the transition period, the MIRD Committee recommends that the 3 absorbed dose values, for $\alpha$-, electron, and photon emissions, be provided separately and reported in the absorbed dose unit, gray. This removes any ambiguity as to interpretation of reported absorbed doses for $\alpha$-emitter therapy applications.

\section{Daughters}

The example provided above is for an $\alpha$-emitter with a relatively simple decay scheme. Each disintegration of the parent ${ }^{213} \mathrm{Bi}$ leads to a single $\alpha$-particle emission; there are no long-lived $\alpha$-emitting daughters. This is not the case for the longer-lived $\alpha$-emitters ${ }^{223} \mathrm{Ra},{ }^{225} \mathrm{Ac}$, and ${ }^{227} \mathrm{Th}$, which decay via $\alpha$-emitting daughters. Because emission of an $\alpha$-particle by the parent atom leads to a $50-$ to $100-\mathrm{nm}$ recoil of the resulting daughter, daughter atoms may not remain conjugated to the molecular carrier. In the most complex scenario, the biologic distribution of the daughter will depend on the site of parent decay (124). In practice, the biologic distribution of long-lived daughters tends to be dominated by the chemical fate of the daughter atom. For example, ${ }^{213} \mathrm{Bi}$, the longest-lived daughter of ${ }^{225} \mathrm{Ac}$, concentrates in the kidneys. Likewise, ${ }^{223} \mathrm{Ra}$, the daughter of ${ }^{227} \mathrm{Th}$, localizes to bone. Dosimetry calculations for such radionuclides must, therefore, account for the biodistribution of both the parent and all daughters.

\begin{tabular}{|c|c|c|}
\hline Isotope & $\begin{array}{c}\text { Photon } \\
\text { energy (keV) }\end{array}$ & $\mathrm{S}$ factor (Gy/MBq-s) \\
\hline${ }^{213} \mathrm{Bi}$ & 440 & $5.78 \mathrm{E}-11$ \\
\hline${ }^{213} \mathrm{Bi}$ & 79 & $9.84 \mathrm{E}-13$ \\
\hline${ }^{209} \mathrm{TI}$ & 117 & $1.60 \mathrm{E}-12$ \\
\hline${ }^{209} \mathrm{TI}$ & 467 & $6.71 \mathrm{E}-12$ \\
\hline${ }^{209} \mathrm{TI}$ & 1,566 & $2.37 E-11$ \\
\hline Sum $=S_{W B \leftarrow W B}$ & & $9.08 \mathrm{E}-11$ \\
\hline
\end{tabular}




\section{ACKNOWLEDGMENT}

We thank David E. Charlton for providing guidance, vigorous discussions, and for his critical reading of the manuscript.

\section{REFERENCES}

1. Bloomer WD, McLaughlin WH, Lambrecht RM, et al. ${ }^{211}$ At radiocolloid therapy: further observations and comparison with radiocolloids of ${ }^{32} \mathrm{P},{ }^{165} \mathrm{Dy}$, and ${ }^{90}$ Y. Int J Radiat Oncol Biol Phys. 1984;10:341-348.

2. Macklis RM, Kinsey BM, Kassis AI, et al. Radioimmunotherapy with alphaparticle emitting immunoconjugates. Science. 1988;240:1024-1026.

3. Zalutsky MR, Vaidyanathan G. Astatine-211-labeled radiotherapeutics: an emerging approach to targeted alpha-particle radiotherapy. Curr Pharm Des. 2000;6:1433-1455.

4. McDevitt MR, Ma D, Lai LT, et al. Tumor therapy with targeted atomic nanogenerators. Science. 2001;294:1537-1540.

5. McDevitt MR, Sgouros G, Finn RD, et al. Radioimmunotherapy with alphaemitting nuclides. Eur J Nucl Med. 1998;25:1341-1351.

6. Mulford DA, Scheinberg DA, Jurcic JG. The promise of targeted $\alpha$-particle therapy. J Nucl Med. 2005;46(suppl 1):199S-204S.

7. Jurcic JG. Antibody therapy for residual disease in acute myelogenous leukemia. Crit Rev Oncol Hematol. 2001;38:37-45.

8. Wilbur DS. Potential use of alpha-emitting radionuclides in the treatment of cancer. Antibody Immunoconjugates Radiopharm. 1990;4:85-97.

9. Wicha MS. Cancer stem cells and metastasis: lethal seeds [commentary]. Clin Cancer Res. 2006;12:5606-5607.

10. Sgouros G, Song H. Cancer stem cell targeting using the alpha-particle emitter, ${ }^{213} \mathrm{Bi}$ : mathematical modeling and feasibility analysis. Cancer Biother Radiopharm. 2008;23:74-81.

11. Jurcic JG, Larson SM, Sgouros G, et al. Targeted alpha particle immunotherapy for myeloid leukemia. Blood. 2002;100:1233-1239.

12. Jurcic JG, McDevitt MR, Sgouros G, et al. Targeted alpha-particle therapy for myeloid leukemias: a phase I trial of bismuth-213-HuM195 (anti-CD33) [abstract]. Blood. 1997;90:2245.

13. Geerlings MW, Kaspersen FM, Apostolidis C, van der Hout R. The feasibility of ${ }^{225} \mathrm{Ac}$ as a source of alpha-particles in radioimmunotherapy. Nucl Med Commun. 1993;14:121-125.

14. Zalutsky MR, Reardon DA, Akabani G, et al. Clinical experience with alphaparticle emitting ${ }^{211} \mathrm{At}$ : treatment of recurrent brain tumor patients with ${ }^{211} \mathrm{At}$ labeled chimeric antitenascin monoclonal antibody 81C6. J Nucl Med. 2008;49:30-38.

15. Nilsson S, Larsen RH, Fossa SD, et al. First clinical experience with alphaemitting radium-223 in the treatment of skeletal metastases. Clin Cancer Res. 2005; 11:4451-4459.

16. Hultborn R, Andersson H, Back T, et al. Pharmacokinetics and dosimetry of ${ }^{211}$ At-MX35 $\mathrm{F}\left(\mathrm{AB}^{\prime}\right)(2)$ in therapy of ovarian cancer: preliminary results from an ongoing phase I study [abstract]. Cancer Biother Radiopharm. 2006;21:395.

17. Kennel SJ, Mirzadeh S, Eckelman WC, et al. Vascular-targeted radioimmunotherapy with the alpha-particle emitter ${ }^{211}$ At. Radiat Res. 2002;157:633-641.

18. Kennel SJ, Mirzadeh S. Vascular targeted radioimmunotherapy with ${ }^{213} \mathrm{Bi}$ : an alpha-particle emitter. Nucl Med Biol. 1998;25:241-246.

19. Akabani G, McLendon RE, Bigner DD, Zalutsky MR. Vascular targeted endoradiotherapy of tumors using alpha-particle-emitting compounds: theoretical analysis. Int J Radiat Oncol Biol Phys. 2002;54:1259-1275.

20. McDevitt MR, Ma D, Simon J, Frank RK, Scheinberg DA. Design and synthesis of ${ }^{225}$ Ac radioimmunopharmaceuticals. Appl Radiat Isot. 2002;57:841-847.

21. Jurcic JG, McDevitt MR, Pandit-Taskar N, et al. Alpha-particle immunotherapy for acute myeloid leukemia (AML) with bismuth-213 and actinium-225 [abstract]. Cancer Biother Radiopharm. 2006;21:396.

22. Zirkle RE. Some effects of alpha radiation upon plant cells. J Cell Comp Physiol. 1932;2:251-274.

23. Brown A, Suit H. The centenary of the discovery of the Bragg peak. Radiother Oncol. 2004;73:265-268.

24. Barendsen GW, Koot CJ, van Kerson GR, Bewley DK, Field SB, Parnell CJ. The effect of oxygen on the impairment of the proliferative capacity of human cells in culture by ionizing radiations of different LET. Int J Radiat Biol. 1966;10:317-327.

25. Barendsen GW, Walter HMD. Effects of different ionizing radiations on human cells in tissue culture. IV. Modification of radiation damage. Radiat Res. 1964;21:314-329.
26. Barendsen GW. Modification of radiation damage by fractionation of dose anoxia + chemical protectors in relation to LET. Ann N Y Acad Sci. 1964;114(A1):96-114.

27. Barendsen GW. Impairment of the proliferative capacity of human cells in culture by alpha-particles with differing linear-energy transfer. Int J Radiat Biol Relat Stud Phys Chem Med. 1964;8:453-466.

28. Barendsen GW, Walter HMD, Bewley DK, Fowler JF. Effects of different ionizing radiations on human cells in tissue culture. III. Experiments with cyclotron-accelerated alpha-particles and deuterons. Radiat Res. 1963;18:106.

29. Barendsen GW. Dose-survival curves of human cells in tissue culture irradiated with alpha-, beta-, 20-kv x- and 200-kv x-radiation. Nature. 1962;193:1153.

30. Barendsen GW, Beusker TLJ. Effects of different ionizing radiations on human cells in tissue culture. I. Irradiation techniques and dosimetry. Radiat Res. 1960;13:832-840.

31. Barendsen GW, Beusker TLJ, Vergroesen AJ, Budke L. Effect of different ionizing radiations on human cells in tissue culture. II. Biological experiments. Radiat Res. 1960;13:841-849.

32. Barendsen GW, Vergroesen AJ. Irradiation of human cells in tissue culture with alpha-rays, beta-rays and x-rays [abstract]. Int J Radiat Biol Relat Stud Phys Chem Med. 1960;2:441.

33. Goodhead DT, Munson RJ, Thacker J, Cox R. Mutation and inactivation of cultured mammalian cells exposed to beams of accelerated heavy ions. IV. Biophysical interpretation. Int J Radiat Biol Relat Stud Phys Chem Med. 1980;37:135-167.

34. Munson RJ, Bance DA, Stretch A, Goodhead DT. Mutation and inactivation of cultured mammalian cells exposed to beams of accelerated heavy ions. I. Irradiation facilities and methods. Int J Radiat Biol Relat Stud Phys Chem Med. 1979;36:127-136.

35. Thacker J, Stretch A, Stephens MA. Mutation and inactivation of cultured mammalian cells exposed to beams of accelerated heavy ions. II. Chinese hamster V79 cells. Int J Radiat Biol Relat Stud Phys Chem Med. 1979;36:137-148.

36. Cox R, Masson WK. Mutation and inactivation of cultured mammalian cells exposed to beams of accelerated heavy ions. III. Human diploid fibroblasts. Int J Radiat Biol Relat Stud Phys Chem Med. 1979;36:149-160.

37. Fisher DR, Frazier ME, Andrews TK Jr. Energy distribution and the relative biological effects of internal alpha emitters. Radiat Prot Dosimetry. 1985;13:223-227.

38. Humm JL, Chin LM. A model of cell inactivation by alpha-particle internal emitters. Radiat Res. 1993;134:143-150.

39. Kvinnsland Y, Stokke T, Aurlien E. Radioimmunotherapy with alpha-particle emitters: microdosimetry of cells with a heterogeneous antigen expression and with various diameters of cells and nuclei. Radiat Res. 2001;155:288-296.

40. Neti PVSV, Howell RW. Log normal distribution of cellular uptake of radioactivity: implications for biologic responses to radiopharmaceuticals. J Nucl Med. 2006;47:1049-1058.

41. Munro TR. Relative radiosensitivity of nucleus and cytoplasm of Chinese hamster fibroblasts. Radiat Res. 1970;42:451-470.

42. Lloyd EL, Gemmell MA, Henning CB, Gemmell DS, Zabransky BJ. Cell survival following multiple-track alpha particle irradiation. Int J Radiat Biol Relat Stud Phys Chem Med. 1979;35:23-31.

43. Raju MR, Eisen Y, Carpenter S, Inkret WC. Radiobiology of alpha particles. III. Cell inactivation by alpha particle traversals of the cell nucleus. Radiat Res. 1991;128:204-209.

44. Bird RP, Rohrig N, Colvett RD, Geard CR, Marino SA. Inactivation of synchronized Chinese hamster V79 cells with charged-particle track segments. Radiat Res. 1980;82:277-289.

45. Todd P, Wood JCS, Walker JT, Weiss SJ. Lethal, potentially lethal, and nonlethal damage induction by heavy-ions in cultured human-cells. Radiat Res. 1985;104(suppl):S5-S12.

46. Roberts CJ, Goodhead DT. The effect of ${ }^{238} \mathrm{Pu}$ alpha-particles on the mouse fibroblast cell line C3H 10T1/2: characterization of source and RBE for cell survival. Int J Radiat Biol Relat Stud Phys Chem Med. 1987;52:871-882.

47. Barendsen GW. LET dependence of linear and quadratic terms in doseresponse relationships for cellular-damage: correlations with the dimensions and structures of biological targets. Radiat Prot Dosimetry. 1990;31:235-239.

48. Howell RW, Rao DV, Hou DY, Narra VR, Sastry KSR. The question of relative biological effectiveness and quality factor for auger emitters incorporated into proliferating mammalian cells. Radiat Res. 1991;128:282-292.

49. Macklis RM, Lin JY, Beresford B, Atcher RW, Hines JJ, Humm JL. Cellular kinetics, dosimetry, and radiobiology of alpha-particle radioimmunotherapy: induction of apoptosis. Radiat Res. 1992;130:220-226.

50. Charlton DE, Nikjoo H, Humm JL. Calculation of initial yields of single-strand and double-strand breaks in cell-nuclei from electrons, protons and alphaparticles. Int J Radiat Biol. 1989;56:1-19. 
51. Charlton DE, Turner MS. Use of chord lengths through the nucleus to simulate the survival of mammalian cells exposed to high LET alpha-radiation. Int $J$ Radiat Biol. 1996;69:213-217.

52. Crawford-Brown DJ, Hofmann W. A generalized state-vector model for radiation-induced cellular transformation. Int J Radiat Biol. 1990;57:407-423.

53. Crawford-Brown DJ, Hofmann W. Correlated hit probability and cell transformation in an effect-specific track length model applied to in vitro alpha irradiation. Radiat Environ Biophys. 2001;40:317-323.

54. Holthusen H. Articles on the biology of radiation effects: analysis on nematode eggs. Pflugers Arch Gesamte Physiol Menschen Tiere. 1921;187:1-24.

55. Thomlinson RH, Gray LH. The histological structure of some human lung cancers and the possible implications for radiotherapy. Br J Cancer. 1955;9:539-549.

56. Unruh A, Ressel A, Mohamed HG, et al. The hypoxia-inducible factor-1 alpha is a negative factor for tumor therapy. Oncogene. 2003;22:3213-3220.

57. Ewing D, Powers EL. Oxygen-dependent sensitization of irradiated cells. In: Meyn RE, Withers HR, eds. Radiation Biology in Cancer Research. New York, NY: Raven Press; 1979:143-168.

58. Hall EJ. Radiobiology for the Radiologist. Philadelphia, PA: JB Lippincott Co.; 1994:118.

59. Machinami R, Ishikawa Y, Boecker BB. The international workshop on health effects of Thorotrast, radium, radon and other alpha-emitters, 1999 [preface]. Radiat Res. 1999;152(suppl):S1-S2.

60. International Commission on Radiological Protection. Relative Biological Effectiveness (RBE), Quality Factor $(Q)$, and Radiation Weighting Factor $\left(w_{R}\right)$. Philadelphia, PA: Elsevier; 2004. ICRP publication 92.

61. Harrison JD, Muirhead CR. Quantitative comparisons of cancer induction in humans by internally deposited radionuclides and external radiation. Int $J$ Radiat Biol. 2003;79:1-13.

62. Brown I, Mitchell JS. The development of a [At-211]-astatinated endoradiotherapeutic drug: Part IV-late radiation effects. Int J Radiat Oncol Biol Phys. 1998;40:1177-1183.

63. Durbin PW, Asling CW, Johnston ME, et al. The induction of tumors in the rat by astatine-211. Radiat Res. 1958;9:378-397.

64. Yokoro K, Kunii A, Furth J, Durbin PW. Tumor induction with astatine-211 in rats: characterization of pituitary tumors. Cancer Res. 1964;24:683-688.

65. Hall EJ, Brenner DJ. The radiobiology of radiosurgery: rationale for different treatment regimes for AVMs and malignancies. Int J Radiat Oncol Biol Phys. 1993;25:381-385.

66. Dale RG, Jones B. The assessment of RBE effects using the concept of biologically effective dose. Int J Radiat Oncol Biol Phys. 1999;43:639-645.

67. Takata M, Sasaki MS, Sonoda E, et al. Homologous recombination and nonhomologous end-joining pathways of DNA double-strand break repair have overlapping roles in the maintenance of chromosomal integrity in vertebrate cells. EMBO J. 1998; 17:5497-5508.

68. Oliveira NG, Castro M, Rodrigues AS, et al. Wortmannin enhances the induction of micronuclei by low and high LET radiation [erratum]. Mutagenesis. 2003;18:217.

69. Oliveira NG, Castro M, Rodrigues AS, et al. Wortmannin enhances the induction of micronuclei by low and high LET radiation. Mutagenesis. 2003; $18: 37-44$.

70. Harapanhalli RS, Narra VR, Yaghmai V, et al. Vitamins as radioprotectors in vivo. II. Protection by vitamin A and soybean oil against radiation-damage caused by internal radionuclides. Radiat Res. 1994;139:115-122.

71. Narra VR, Harapanhalli RS, Goddu SM, Howell RW, Rao DV. Radioprotection against biological effects of internal radionuclides in vivo by $\mathrm{S}$-(2-aminoethyl)isothiouronium bromide hydrobromide (AET). J Nucl Med. 1995;36:259-266.

72. Rao DV, Howell RW, Narra VR, Govelitz GF, Sastry KSR. In-vivo radiotoxicity of DNA-incorporated ${ }^{125} \mathrm{I}$ compared with that of densely ionizing alphaparticles. Lancet. 1989;2:650-653.

73. Rao DV, Narra VR, Howell RW, Lanka VK, Sastry KSR. Induction of sperm head abnormalities by incorporated radionuclides: dependence on subcellular distribution, type of radiation, dose rate, and presence of radioprotectors. Radiat Res. 1991;125:89-97.

74. Goddu SM, Narra VR, Harapanhalli RS, Howell RW, Rao DV. Radioprotection by DMSO against the biological effects of incorporated radionuclides in vivo: comparison with other radioprotectors and evidence for indirect action of Auger electrons. Acta Oncol. 1996;35:901-907.

75. Narra VR, Harapanhalli R, Howell RW, Sastry KSR, Rao DV. Vitamins as radioprotectors in vivo. I. Protection by vitamin $\mathrm{C}$ against internal radionuclides in mouse testes: implications to the mechanism of damage caused by the Auger effect. Radiat Res. 1994;137:394-399.

76. Wright HA, Magee JL, Hamm RN, Chatterjee A, Turner JE, Klots CE. Calculations of physical and chemical-reactions produced in irradiated water containing DNA. Radiat Prot Dosimetry. 1985;13:133-136.
77. International Commission on Radiological Protection. RBE for Deterministic Effects. Philadelphia, PA: Elsevier; 1990. ICRP publication 58.

78. Schwartz JL, Rotmensch J, Atcher RW, et al. Interlaboratory comparison of different alpha-particle and radon sources: cell survival and relative biological effectiveness. Health Phys. 1992;62:458-461.

79. Jostes RF, Hui TE, James AC, et al. In vitro exposure of mammalian cells to radon: dosimetric considerations. Radiat Res. 1991;127:211-219.

80. Charlton DE, Utteridge TD, Allen BJ. Theoretical treatment of human haemopoietic stem cell survival following irradiation by alpha particles. Int $J$ Radiat Biol. 1998;74:111-118.

81. Howell RW, Goddu SM, Narra VR, Fisher DR, Schenter RE, Rao DV. Radiotoxicity of gadolinium-148 and radium-223 in mouse testes: relative biological effectiveness of alpha-particle emitters in vivo. Radiat Res. 1997; 147:342-348.

82. Howell RW, Goddu SM, Rao DV. Design and performance characteristics of an experimental cesium-137 irradiator to simulate internal radionuclide dose rate patterns. J Nucl Med. 1997;38:727-731.

83. Goddu SM, Bishayee A, Bouchet LG, Bolch WE, Rao DV, Howell RW. Marrow toxicity of ${ }^{33} \mathrm{P}$-versus ${ }^{32} \mathrm{P}$-orthophosphate: implications for therapy of bone pain and bone metastases. J Nucl Med. 2000;41:941-951.

84. Feinendegen LE, McClure JJ. Meeting report: Alpha-emitters for medical therapy-Workshop of the United States Department of Energy, Denver, Colorado, May 30-31, 1996. Radiat Res. 1997;148:195-201.

85. 1990 recommendations of the International Commission on Radiological Protection. Ann ICRP. 1991;21:1-201.

86. Radiation protection in medicine: ICRP publication 105. Ann ICRP. 2007;37: $1-63$.

87. Neti PVSV, Howell RW. Biological response to nonuniform distributions of ${ }^{210}$ Po in multicellular clusters. Radiat Res. 2007;168:332-340.

88. Goddu SM, Rao DV, Howell RW. Multicellular dosimetry for micrometastases: dependence of self-dose versus cross-dose to cell nuclei on type and energy of radiation and subcellular distribution of radionuclides. $J$ Nucl $\mathrm{Med}$. 1994;35:521-530.

89. Charlton DE. Radiation effects in spheroids of cells exposed to alpha emitters. Int J Radiat Biol. 2000;76:1555-1564.

90. Akabani G, Zalutsky MR. Microdosimetry of astatine-211 using histological images: application to bone marrow. Radiat Res. 1997;148:599-607.

91. Humm JL, Macklis RM, Bump K, Cobb LM, Chin LM. Internal dosimetry using data derived from autoradiographs. J Nucl Med. 1993;34:18111817.

92. Baxter LT, Jain RK. Transport of fluid and macromolecules in tumors. IV. A microscopic model of the perivascular distribution. Microvasc Res. 1991;41:252-272.

93. Jain RK, Baxter LT. Mechanisms of heterogeneous distribution of monoclonal antibodies and other macromolecules in tumors: significance of elevated interstitial pressure. Cancer Res. 1988;48:7022-7032.

94. Sgouros G. Plasmapheresis in radioimmunotherapy of micrometastases: a mathematical modeling and dosimetrical analysis. J Nucl Med. 1992;33: 2167-2179.

95. Goddu SM, Howell RL, Bouchet LG, Bolch WE, Rao DV. MIRD Cellular S Values. Reston VA: Society of Nuclear Medicine; 1997.

96. Goddu SM, Howell RW, Rao DV. Cellular dosimetry: absorbed fractions for monoenergetic electron and alpha particle sources and S-values for radionuclides uniformly distributed in different cell compartments. J Nucl Med. 1994;35:303-316.

97. Polig E. Localized alpha-dosimetry. In: Eberg M, Howard A, eds. Current Topics in Radiation Research. Vol 13. Amsterdam, The Netherlands: Elsevier; 1978:189-327.

98. Rossi HH. Microdosimetric energy distribution in irradiated matter. In: Attx FH, Roesch WC, eds. Radiation Dosimetry. Vol 1. New York, NY: Academic Press; 1968.

99. Roesch WC. Microdosimetry of internal sources. Radiat Res. 1977;70:494510.

100. Fisher DR. The microdosimetry of monoclonal antibodies labeled with alpha emitters. In: Schlafke-Stelson AT, Watson EE, eds. Fourth International Radiopharmaceutical Dosimetry Symposium. Oak Ridge, TN: Oak Ridge Associated Universities; 1986:26-36.

101. Stinchcomb TG, Roeske JC. Analysis of survival of C-18 cells after irradiation in suspension with chelated and ionic bismuth-212 using microdosimetry. Radiat Res. 1994;140:48-54.

102. Stinchcomb TG, Roeske JC. Analytic microdosimetry for radioimmunotherapeutic alpha emitters. Med Phys. 1992;19:1385-1393.

103. Kellerer AM. Analysis of patterns of energy deposition: a survey of theoretical relations in microdosimetry. In: Ebert HG, ed. Proceedings of the Second 
Symposium on Microdosimetry. Brussels, Belgium: Commission of European Communities; 1970:107-134.

104. Olko P, Booz J. Energy deposition by protons and alpha-particles in spherical sites of nanometer to micrometer diameter. Radiat Environ Biophys. 1990;29:1-17.

105. Ziegler JF, Biersack JP, Littmark U. The Stopping and Range of Ions in Matter. New York, NY, Pergamon Press; 1985.

106. Ziegler JF. The stopping and range of ions in solids (Stopping and Range of Ions in Matter, Vol. 1). New York, NY: Pergamon; 1985.

107. Bichsel H. Stopping Powers of Fast Charged Particles in Heavy Elements. Springfield, VA: U.S. National Technical Information Service; 1992. NIST report IR-4550.

108. International Commission on Radiation Units and Measurements. Stopping Powers and Ranges for Protons and Alpha Particles. Bethesda, MD: ICRU; 1993. ICRU publication 49.

109. Kellerer AM, Chmelevsky D. Criteria for applicability of LET. Radiat Res. 1975;63:226-234.

110. Roeske JC, Stinchcomb TG. Dosimetric framework for therapeutic alphaparticle emitters. J Nucl Med. 1997;38:1923-1929.

111. Loevinger R, Budinger TF, Watson EE. MIRD Primer for Absorbed Dose Calculations. Revised ed. New York, NY: Society of Nuclear Medicine; 1991.

112. Stinchcomb TG, Roeske JC. Values of "S," $<\mathrm{z} 1>$, and $<(\mathrm{z} 1) 2>$ for dosimetry using alpha-particle emitters. Med Phys. 1999;26:1960-1971.

113. Fisher DR. Specific energy distributions for alpha emitters in the dog lung. Ann Occup Hyg. 1988;32(suppl 1):1095-1104.

114. Humm JL. A microdosimetric model of astatine-211 labeled antibodies for radioimmunotherapy. Int J Radiat Oncol Biol Phys. 1987;13:1767-1773.

115. Stinchcomb TG, Roeske JC. Survival of alpha particle irradiated cells as a function of the shape and size of the sensitive volume (nucleus). Radiat Prot Dosimetry. 1995;62:157-164.

116. Aubineau-Laniece I, Pihet P, Winkler R, Hofmann W, Charlton DE. Monte Carlo code for microdosimetry of inhaled alpha emitters. Radiat Prot Dosimetry. 2002;99:463-467.

117. Fakir H, Hofmann W, Aubineau-Laniece I. Modelling the effect of non-uniform radon progeny activities on transformation frequencies in human bronchial airways. Radiat Prot Dosimetry. 2006;121:221-235.

118. Fakir H, Hofmann W, Aubineau-Laniece I. Microdosimetry of radon progeny alpha particles in bronchial airway bifurcations. Radiat Prot Dosimetry. 2005; 117:382-394.

119. Fakir H, Hofmann W, Caswell RS, Aubineau-Laniece I. Microdosimetry of inhomogeneous radon progeny distributions in bronchial airways. Radiat Prot Dosimetry. 2005;113:129-139.

120. Palm S, Humm JL, Rundqvist R, Jacobsson L. Microdosimetry of astatine-211 single-cell irradiation: role of daughter polonium-211 diffusion. Med Phys. 2004;31:218-225.

121. Iyer R, Lehnert BE. Alpha-particle-induced increases in the radioresistance of normal human bystander cells. Radiat Res. 2002;157:3-7.

122. Azzam EI, de Toledo SM, Gooding T, Little JB. Intercellular communication is involved in the bystander regulation of gene expression in human cells exposed to very low fluences of alpha particles. Radiat Res. 1998;150:497-504.

123. Utteridge TD, Charlton DE, Allen BJ. Monte Carlo modeling of the effects of injected short-, medium- and longer-range alpha-particle emitters on human marrow at various ages. Radiat Res. 2001;156:413-418.

124. Hamacher KA, Sgouros G. A schema for estimating absorbed dose to organs following the administration of radionuclides with multiple unstable daughters: a matrix approach. Med Phys. 1999;26:2526-2528.

125. Fisher DR, Sgouros G. Dosimetry of radium-223 and progeny. In: Stelson AT, Stabin MG, Sparks RB, eds. Proceedings of the Sixth International Radiopharmaceutical Dosimetry Symposium. Gatlinburg, TN: U.S. Department of Energy and Oak Ridge Associated Universities; 1999:375-391.

126. Sgouros G. Long-lived alpha emitters in radioimmunotherapy: the mischievous progeny. Cancer Biother Radiopharm. 2000;15:219-221.

127. Miederer M, McDevitt MR, Sgouros G, Kramer K, Cheung NK, Scheinberg DA. Pharmacokinetics, dosimetry, and toxicity of the targetable atomic generator, ${ }^{225}$ Ac-HuM195, in nonhuman primates. $J$ Nucl Med. 2004;45:129-137.

128. Hamacher KA, Den RB, Den EI, Sgouros G. Cellular dose conversion factors for alpha-particle-emitting radionuclides of interest in radionuclide therapy. J Nucl Med. 2001;42:1216-1221.

129. Muller WA. Studies on short-lived internal alpha-emitters in mice and rats. II. ${ }^{227}$ Th. Int J Radiat Biol Relat Stud Phys Chem Med. 1971;20:233-243.

130. Dahle J, Borrebaek J, Melhus KB, et al. Initial evaluation of ${ }^{227}$ Th-p-benzylDOTA-rituximab for low-dose rate alpha-particle radioimmunotherapy. Nucl Med Biol. 2006;33:271-279.

131. Dahle J, Borrebaek J, Jonasdottir TJ, et al. Targeted cancer therapy with a novel low dose rate alpha-emitting radioimmunoconjugate. Blood. 2007;110:2049-2056.
132. Siegel JA, Thomas SR, Stubbs JB, et al. MIRD pamphlet no. 16: techniques for quantitative radiopharmaceutical biodistribution data acquisition and analysis for use in human radiation dose estimates. $J$ Nucl Med. 1999;40(suppl):37S-61S.

133. Sgouros G. Treatment planning for internal emitter therapy: methods, applications and clinical implications. In: Schafke-Stelson AT, Watson EE, eds. Proceedings of the 6th International Radiopharmaceutical Dosimetry Symposium, May 7-10, 1996, Gatlinburg, TN. Oak Ridge, TN: Oak Ridge Associated Universities; 1996:13-24.

134. Sgouros G. Radioimmunotherapy of micrometastases. In: Riva P, ed. Cancer Radioimmunotherapy: Present and Future. Newark, NJ: Harwood Academic Publishers; 1998:191-207.

135. Kirschner AS, Ice RD, Beierwaltes WH. Radiation dosimetry of ${ }^{131}$ I-19iodocholesterol: the pitfalls of using tissue concentration data [reply]. J Nucl Med. 1975;16:248-249.

136. Sgouros G, Ballangrud AM, Jurcic JG, et al. Pharmacokinetics and dosimetry of an alpha-particle emitter labeled antibody: ${ }^{213} \mathrm{Bi}-\mathrm{HuM} 195$ (anti-CD33) in patients with leukemia. J Nucl Med. 1999;40:1935-1946.

137. Patton PW, Rajon DA, Shah AP, Jokisch DW, Inglis BA, Bolch WE. Sitespecific variability in trabecular bone dosimetry: considerations of energy loss to cortical bone. Med Phys. 2002;29:6-14.

138. Bolch WE, Patton PW, Rajon DA, Shah AP, Jokisch DW, Inglis BA. Considerations of marrow cellularity in 3-dimensional dosimetric models of the trabecular skeleton. J Nucl Med. 2002;43:97-108.

139. Shah AP, Patton PW, Rajon DA, Bolch WE. Adipocyte spatial distributions in bone marrow: implications for skeletal dosimetry models. J Nucl Med. 2003;44:774-783.

140. Shah AP, Rajon DA, Patton PW, Jokisch DW, Bolch WE. Accounting for betaparticle energy loss to cortical bone via paired-image radiation transport (PIRT). Med Phys. 2005;32:1354-1366.

141. Watchman CJ, Jokisch DW, Patton PW, Rajon DA, Sgouros G, Bolch WE. Absorbed fractions for alpha-particles in tissues of trabecular bone: considerations of marrow cellularity within the ICRP reference male. J Nucl Med. 2005; 46:1171-1185.

142. Bolch WE, Eckerman KF, Sgouros G, Thomas SR. MIRD pamphlet no. 21: a generalized schema for radiopharmaceutical dosimetry-standardization of nomenclature. J Nucl Med. 2009;50:477-484.

143. Eckerman KF, Endo A. MIRD: Radionuclide Data and Decay Schemes. Reston, VA: Society of Nuclear Medicine; 2007.

144. Snyder WS, Fisher HL, Ford MR, Warner GG. Estimates of absorbed fractions for monoenergetic photon sources uniformly distributed in various organs of a heterogeneous phantom. J Nucl Med. 1969;10(suppl):7-52.

145. Bouchet LG, Jokisch DW, Bolch WE. A three-dimensional transport model for determining absorbed fractions of energy for electrons within trabecular bone. J Nucl Med. 1999;40:1947-1966.

146. Snyder WS, Ford MR, Warner GG. MIRD Pamphlet No. 5, Revised: Estimates of Specific Absorbed Fractions for Photon Sources Uniformly Distributed in Various Organs of a Heterogeneous Phantom. New York, NY: Society of Nuclear Medicine; 1978.

147. Sgouros G, Howell RW, Bolch WE, Fisher DR. MIRD commentary: proposed name for a dosimetry unit applicable to deterministic biological effects- the Barendsen (Bd). J Nucl Med. 2009;50:485-487.

148. Kneifel S, Cordier D, Good S, et al. Local targeting of malignant gliomas by the diffusible peptidic vector 1,4,7,10-tetraazacyclododecane-1-glutaric acid4,7,10-triacetic acid-substance P. Clin Cancer Res. 2006;12:3843-3850.

149. Heeger S, Moldenhauer G, Egerer G, et al. Alpha-radioimmunotherapy of B-lineage non-Hodgkin's lymphoma using ${ }^{213} \mathrm{Bi}$-labelled anti-CD19-and antiCD20-CHX-A"-DTPA conjugates [abstract]. Abstracts of Papers of the American Chemical Society. 2003;225:U261.

150. Allen BJ, Raja C, Rizvi S, et al. Intralesional targeted alpha therapy for metastatic melanoma. Cancer Biol Ther. 2005;4:1318-1324.

151. Bruland OS, Nilsson S, Fisher DR, Larsen RH. High-linear energy transfer irradiation targeted to skeletal metastases by the alpha-emitter Ra-223: adjuvant or alternative to conventional modalities? Clin Cancer Res. 2006;12(suppl): 6250S-6257S.

152. Nilsson S, Franzen L, Parker C, et al. Bone-targeted radium-223 in symptomatic, hormone-refractory prostate cancer: a randomised, multicentre, placebo-controlled phase II study. Lancet Oncol. 2007;8:587-594.

153. Goodhead DT. Talk 23, Alpha Emitters, from Session 6, Effects from Specific Sources of Internal Radiation. Presented at: CERRIE Workshop; July 21-23, 2003; Oxford, U.K.

154. Powsner RA, Powsner ER. Essentials of Nuclear Medicine Physics. Malden MA: Blackwell Science, Inc.; 1998.

155. Cole A, ed. Theoretical and Experimental Biophysics. New York, NY: Marcel Dekker, Inc.; 1967. 